\title{
Aspergillus caespitosus ASEF14, an oleaginous fungus as a potential candidate for biodiesel production using sago processing wastewater (SWW)
}

\author{
Naganandhini Srinivasan ${ }^{1}$, Kiruthika Thangavelu², Ashika Sekar ${ }^{1}$, B. Sanjeev ${ }^{1}$ and Sivakumar Uthandi ${ }^{*}$ (D)
}

\begin{abstract}
Background: Oleaginous microorganisms are sustainable alternatives for the production of biodiesel. Among them, oleaginous fungi are known for their rapid growth, short life cycles, no light requirement, easy scalability, and the ability to grow in cheap organic resources. Among all the sources used for biodiesel production, industrial wastewater streams have been least explored. We used oleaginous fungi to decontaminate sago processing wastewater and produce biodiesel.
\end{abstract}

Results: Among the 15 isolates screened for lipid production and starch utilization using the Nile red staining assay and amylase plate screening, three isolates accumulated $>20 \%(\mathrm{w} / \mathrm{w})$ of their dry cell mass as lipids. The isolate ASEF14 exhibited the highest lipid accumulation (>40\%) and was identified as Aspergillus caespitosus based on the $28 \mathrm{~S}$ rRNA gene sequencing. The maximum lipid content of 54.4\% in synthetic medium (SM) and $37.2 \%$ in sago processing wastewater (SWW) was produced by the strain. The Fourier-transform infrared (FTIR) spectroscopy of the fungal oil revealed the presence of functional peaks corresponding to major lipids. Principal component analysis (PCA) of the FTIR data revealed major changes in the fatty acid composition during the transition from the growth phase (Days 1-3) to the lipid accumulation phase (Days 4-7). The fatty acid methyl esters (FAME) analysis of fungal oil from SWW contained $43.82 \%$ and $9.62 \%$ of saturated and monounsaturated fatty acids, respectively. The composition and percentage of individual FAME derived from SWW were different from SM, indicating the effect of nutrient and fermentation time. The fuel attributes of the SM- and SWW-grown fungal biodiesel (kinematic viscosity, iodine value, cetane number, cloud and pour point, linolenic acid content, FA > 4 double bonds) met international (ASTM D6751, EN 14214) and national (IS 15607) biodiesel standards. In addition to biodiesel production, the strain removed various contaminants such as total solids (TS), total suspended solids (TSS), total dissolved solids (TDS), dissolved oxygen (DO), chemical oxygen demand (COD), biological oxygen demand (BOD), total nitrogen (TN), total phosphorus (TP), and cyanide up to 58.6\%, 53.0\%, 35.2\%, 94.5\%, 89.3\%, 91.3\%, 74.0\%, 47.0\%, and 53.84\%, respectively, from SWW.

Conclusion: These findings suggested that A. caespitosus ASEF14 is a potential candidate with high lipid accumulating ability (37.27\%), capable of using SWW as the primary growth medium. The medium and incubation time alter the FAME profile of this fungus. The physical properties of fungal oil were in accordance with the biodiesel standards.

*Correspondence: usivakumartnau@gmail.com

1 Biocatalysts Laboratory, Deptartment of Agricultural Microbiology, Tamil

Nadu Agricultural University, Coimbatore 641 003, India

Full list of author information is available at the end of the article

(c) The Author(s) 2021. Open Access This article is licensed under a Creative Commons Attribution 4.0 International License, which permits use, sharing, adaptation, distribution and reproduction in any medium or format, as long as you give appropriate credit to the original author(s) and the source, provide a link to the Creative Commons licence, and indicate if changes were made. The images or other third party material in this article are included in the article's Creative Commons licence, unless indicated otherwise in a credit line to the material. If material is not included in the article's Creative Commons licence and your intended use is not permitted by statutory regulation or exceeds the permitted use, you will need to obtain permission directly from the copyright holder. To view a copy of this licence, visit http://creativecommons.org/licenses/by/4.0/. The Creative Commons Public Domain Dedication waiver (http://creativeco mmons.org/publicdomain/zero/1.0/) applies to the data made available in this article, unless otherwise stated in a credit line to the data. 
Moreover, it decontaminated SWW by reducing several polluting nutrients and toxicants. The fungal biodiesel produced by this cost-effective method could serve as an alternate path to meet global energy demand.

Keywords: Aspergillus, Biodiesel, Lipid content, Sago wastewater, Decontamination

\section{Background}

With the increasing depletion of fossil fuels, there is an urgent need to search for viable substitutes to fulfill the energy requirements of society. A suitable substitute for fossil fuels would be an alternative fuel with superior environmental benefits over fossil fuels, economically competitive, and producible in sufficient quantities to meet the increasing energy demands. In addition, it must provide a net energy gain over the energy sources used to produce it [1]. Recently, biodiesel has received considerable attention as an alternative to fossil fuels. Although more than $80 \%$ of biodiesel is obtained from plant oil globally, it is unable to meet the current demand. Furthermore, it creates a fuel versus food fight, with negative consequences on consumers and the agricultural system.

The most hindering aspect of the commercialization of biodiesel production has been the high cost of raw material, especially that of currently used plant oils [2]. The oily or oleaginous microbes are being investigated worldwide as an alternative sustainable feedstock to plant oils for biodiesel production [3]. These oil-rich microbes can accumulate fatty acids (FA) up to $70 \%$ of their dry weight, with a predominance of (mono)unsaturated fatty acids species, which is similar to plants, different from animals [4]. In addition, these microbes do not compete either with food, feed crops, or agricultural land and have the ability to manufacture and accumulate high quantities of triacylglycerols (TAGs). These TAGs could be converted to biodiesel through transesterification, which involves converting methanol and TAGs into biodiesel in the presence of an acid or base as a catalyst [5].

Oleaginous yeast and fungi have emerged as the most promising candidate for biodiesel production due to their optimal and diverse fatty acid profiles, pelleted growth that allows easier and cost-effective downstream processing, ability to degrade and grow on a wide range of renewable sources, such as lignocellulosic biomass [6-8], waste glycerol [9], waste cooking oil [10, 11], and industrial waste streams [12-14]. Industrial wastewater streams have been least explored.

The production of sago from tapioca is one of the most significant agro-based food industries in SouthEast Asia. There are approximately 1000 sago-processing factories that are currently operational in Salem and Namakkal Districts of Tamil Nadu, India. Sago industrial plants release a huge volume of wastewater rich in organic and inorganic compounds, especially starch. The waste is discharged into the nearby river, causing detrimental effects to the environment. Therefore, recycling, reprocessing, and reuse of these waste streams in an ecofriendly manner is important. All organic waste materials contain adequate quantities of nutrients that support the growth and metabolism of microbes. The use of waste streams as a substrate for oleaginous microbes would be an effective strategy to improve the process economics of biodiesel production $[15,16]$. Earlier reports have suggested the potential of industrial waste streams for microbial lipid production using oleaginous microbes. For example, Xue et al. [12] successfully cultured the oleaginous yeast Rhodotorula glutinis in monosodium glutamate wastewater, producing $25 \mathrm{~g} \mathrm{~L}^{-1}$ biomass with 25\% lipid content. Similarly, a culture of Aspergillus niger accumulated $41 \%$ to $57 \%$ of lipids in biodiesel-derived waste glycerol [9]. Muniraj et al. [13] used various diluted potato-processing wastewater (PPW) as a growth medium for $A$. oryzae and obtained a $3.5 \mathrm{~g} \mathrm{~L}^{-1}$ lipid yield at $25 \%$ diluted PPW. In addition, the removal of COD, total soluble nitrogen, and total soluble phosphorus up to $91 \%, 98 \%$, and $97 \%$, respectively, were achieved. A. flavus I16-3 and $M$. rouxii grew well and efficiently used the starch in PPW and produced 2.8 and $3.6 \mathrm{~g} \mathrm{~L}^{-1}$ of lipids, respectively [17].

We previously reported that the oleaginous yeast Candida tropicalis ASY2 produced $1.21 \mathrm{~g} \mathrm{~L}^{-1}$ of lipid (lipid content: $48.59 \%)$ when cultivated in SWW [14, 18]. Further, we characterized the yeast biomass for its bioenergy applications [19]. In the present study, we screened different morpho-type fungi from SWW for its amylase production and oleaginicity, and investigated the growth, lipid production and decontaminating ability of $A$. caespitosus ASEF14 in SWW. The fungal biomass generated was used to produce FAMEs by direct transesterification and evaluated for potential biodiesel's fuel properties.

\section{Materials and methods Chemicals and reagents}

Nile red (NR) dye and FAME mix was purchased from Sigma-Aldrich Pvt. Ltd. (St Louis, MO, USA). Analytical grade solvents, such as isopropanol, ethanol, chloroform, methanol, and other chemicals, were obtained from commercial suppliers such as HiMedia, Merck, Central Drug House, and SRL Laboratory. 
Sago-processing wastewater (SWW) collection and analysis SWW was collected in an air-tight container from Sri Senthil Andavar Sago industry located in Salem District, Tamil Nadu, India, and stored at $4{ }^{\circ} \mathrm{C}$. The physicochemical properties of SWW were analyzed immediately after transport, following the standard method of water and wastewater analysis [20]. Biological oxygen demand (BOD) was measured according to the closed bottle test, and chemical oxygen demand (COD) was measured by the dichromate method using the Soxhlet apparatus. The total nitrogen and phosphorus were determined by Kjeldahl [21] and colorimetric methods, respectively. The starch in SWW was analyzed using the phenol-sulfuric acid method [22]. Cyanide content in SWW was determined using a modified picric acid method [23].

\section{Biotrap enrichment and isolation}

The biotrap enrichment approach was used to isolate oleaginous and starch hydrolyzing fungi from SWW. In this procedure, soluble starch (HiMedia, India) and a substrate called "thippi" (a fibrous waste fraction left in the siever after milky starch passed out during the starch extraction process) were mixed and filled to one-third portion of a $15 \mathrm{~mL}$ Falcon tube. The tube was closed and then placed in a wastewater discharge pipeline. A few micro-holes were made on the surface of the Falcon tube before it was placed in the discharge line in order to keep the tube content in contact with SWW. The enrichment process was carried out for 15 days, as recommended [24-26]. In this way, the starch-utilizing fungi in the SWW were selectively flourished in the tube (Fig. 1).

After 15 days, the enriched samples were serially diluted up to $10^{-4}$ fold dilution. An aliquot of $1 \mathrm{~mL}$ from the final dilutions was plated on sterile potato dextrose agar (PDA) medium containing ampicillin $\left(0.1 \mathrm{mg} \mathrm{mL}^{-1}\right)$ and incubated at room temperature $\left(28 \pm 2{ }^{\circ} \mathrm{C}\right)$ for 3 to 5 days. Single colonies of fungus were isolated, purified using either single spore or single hyphal tip method, and maintained on PDA slants at $4{ }^{\circ} \mathrm{C}$.

\section{Screening of oleaginous fungi Starch-hydrolyzing activity}

Purified fungal isolates were screened for amylase activity by cultivating on starch agar medium containing the following chemical components per liter of the medium: starch, 1 g; peptone, 0.5 g; yeast extract, $0.3 \mathrm{~g} ; \mathrm{NaCl}, 0.3 \mathrm{~g}$; and agar, $20 \mathrm{~g}$ [27]. Individual discs of each fungal isolate that had grown on the starch agar medium for 3 to 5 days were flooded with $1 \%$ iodine solution and observed for clear zones around the fungal colony.

\section{Nile red staining}

All amylase-positive isolates were evaluated for intracellular lipid bodies (LBs), indicative of lipid accumulation, by NR fluorescence staining [28, 29]. An aliquot of $10 \mu \mathrm{L}$ of NR $\left(0.1 \mathrm{mg} \mathrm{mL}^{-1}\right)$ was mixed with the fungal culture suspension, followed by the addition of $2 \mathrm{~mL}$ of phosphate-buffered saline (PBS) to $50 \mu \mathrm{L}$ of culture broth, which was subsequently maintained in the dark for $5 \mathrm{~min}$. The sample was analyzed under a Nikon Eclipse 80i light microscope (Nikon Instruments, Tokyo, Japan) equipped with a digital camera, using a 465 to $495 \mathrm{~nm}$ excitation filter, a $505 \mathrm{~nm}$ diachronic mirror, and a 515 to $535 \mathrm{~nm}$ barrier filter.

\section{Lipid content determination}

The selected fungal isolates were grown in $250 \mathrm{~mL}$ Erlenmeyer flasks containing $50 \mathrm{~mL}$ of modified starch-based SM (composition per liter: starch, $30 \mathrm{~g}$; ammonium sulfate, $0.5 \mathrm{~g}$; potassium dihydrogen phosphate, $7 \mathrm{~g}$; disodium hydrogen phosphate, $2.5 \mathrm{~g}$; magnesium sulfate, $1.5 \mathrm{~g}$; ferric chloride, $0.15 \mathrm{~g}$; calcium chloride, $0.15 \mathrm{~g}$; zinc sulfate, $0.02 \mathrm{~g}$; and manganese sulfate, $0.06 \mathrm{~g}$ ) with a wide C:N ratio of $30: 1$ for seven days at $30^{\circ} \mathrm{C}$ [30]. After incubation, the fungal biomass from the broth culture was separated by filtration, washed with sterile distilled water and oven-dried at $60{ }^{\circ} \mathrm{C}$ for $15 \mathrm{~h}$ [31]. Dried samples were used to determine the lipid content using the method described by Folch et al. [32], using chloroform and methanol (2:1) as solvents.

\section{Phylogeny and identification of ASEF 14}

Genomic DNA was extracted from the high lipid accumulating fungal isolate ASEF14 using the modified CTAB method [33]. DNA concentration and purity were analyzed by Nanodrop ${ }^{\mathrm{TM}} 2000$ spectrophotometer $^{2}$ (Thermo-Fisher, USA) and agarose gel electrophoresis, respectively. PCR amplification of $28 \mathrm{~S}$ rRNA region was performed in a T-gradient thermocycler (BioRad T100 Thermal Cycler, USA) using the universal primers ITS1 (F) 5'-CTTGGTCATTTAGAGGAAGTAA-3' and ITS4 (R) 5'-TCCTCCGCTTATTGATATGC-3', under the following conditions: initial denaturation at $95^{\circ} \mathrm{C}$ for $5 \mathrm{~min}$, followed by 33 cycles of $94{ }^{\circ} \mathrm{C}$ for $30 \mathrm{~s}$ (denaturation), $58{ }^{\circ} \mathrm{C}$ for $1.5 \mathrm{~min}$ (annealing), $72{ }^{\circ} \mathrm{C}$ for $2.5 \mathrm{~min}$ (primer extension), and a final extension at $72{ }^{\circ} \mathrm{C}$ for $7 \mathrm{~min}$. The amplified PCR products were visualized using electrophoresis on $1.5 \%$ agarose gels, followed by purification using spin columns (Qiagen, Germany). The sample was prepared using the $\mathrm{ABI}$ prism terminator cycle sequencing-ready reaction kit and sequenced on an Applied Biosystems (Model 3100) automated sequencer. The identity of the 28S rRNA gene sequence was established 


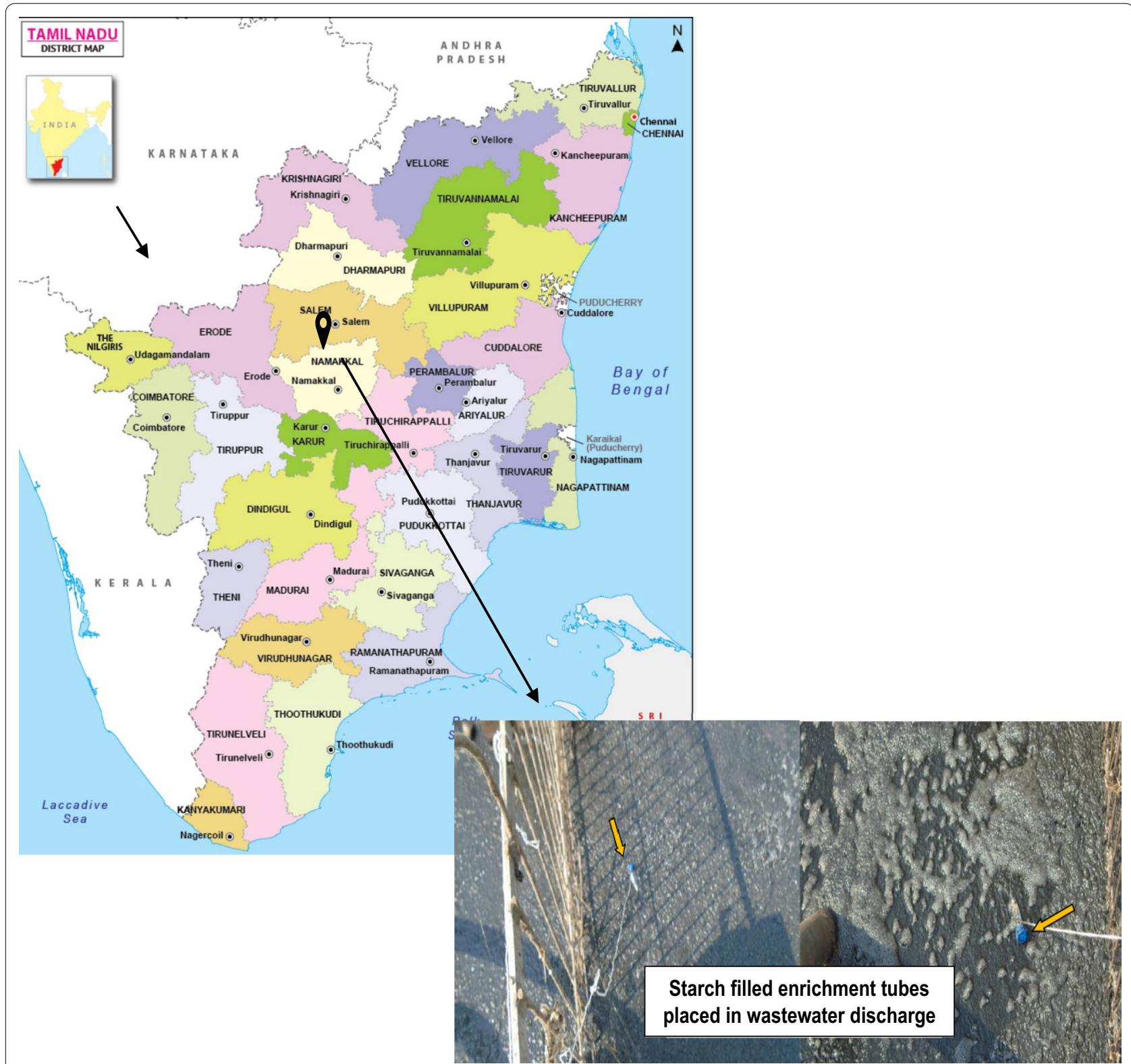

Fig. 1 Enrichment and sample collection from sago-processing industries (location: Salem district, Tamil Nadu, India)

by performing a similarity search against the sequences in the GenBank database (http://www.ncbi.nih.gov/ BLAST). The sequence of ASEF14 was submitted to the National Centre for Biotechnological Information (NCBI) database, and an accession number was obtained. Using the ASEF14 sequence, a phylogenetic tree was constructed using the neighbor-joining method originally described by Saitou N and Nei M [34] in MEGA 5.0 software [35], along with the existing $28 \mathrm{~S}$ rRNA gene sequences from the related Aspergillus sp. obtained from the NCBI GenBank database.

\section{Growth kinetics and lipid production by $A$. caespitosus ASEF14 in SM and SWW}

Based on the high lipid accumulation, amylase secretion, and starch utilization in SM, the superior oleaginous fungus $A$. caespitosus ASEF14 was selected to study their physiological response and lipid accumulation kinetics in SWW as well as SM, respectively. The fungal strain was grown in SM and SWW for ten days at $30^{\circ} \mathrm{C}$. Before inoculation into SWW, the $\mathrm{pH}$ of the SWW was adjusted to near neutral ( $\mathrm{pH}$ 6) with $0.1 \mathrm{~N} \mathrm{NaOH}$. Based on the processing steps in sago production, the starch content 
in SWW was varied (7 to $10 \mathrm{~g} \mathrm{~L}^{-1}$ ). In the present study, the raw SWW contained $6.10 \mathrm{~g} \mathrm{~L}^{-1}$ of starch. Hence, the initial starch concentration of SWW was adjusted to $30 \mathrm{~g}$ $\mathrm{L}^{-1}$, similar to $\mathrm{SM}$.

Periodically, both fungal biomass and spent culture medium were withdrawn from the experimental culture flask for estimating biomass, lipid, starch content, and amylase activity. Cell biomass was determined after harvesting the mycelia from the culture broth using filtration through Whatman No.1 filter paper. The harvested mycelia were washed thoroughly with sterile distilled water and dried in an oven at $60{ }^{\circ} \mathrm{C}$ for $15 \mathrm{~h}$ [31]. Next, the lipids were extracted from the dried biomass using a 2:1 mixture of chloroform and methanol as done for determining the lipid content [32]. The spent culture medium was separated by centrifugation at $5,000 \mathrm{rpm}$ for $10 \mathrm{~min}$, and the supernatant was used to analyze $\mathrm{pH}$, total soluble starch, and amylase activity. The total soluble starch of the culture filtrate was measured using the phenol sulfuric acid method [22]. Amylase activity was measured according to the dinitrosalicylic acid (DNS) method as described by Bernfeld [36].

\section{FTIR spectral analysis of fungal lipids}

The FTIR spectra of standard fatty acid (FAME Mix C4-C24, Sigma-Aldrich, St Louis, MO, USA) and extracted lipids from A. caespitosus ASEF14 grown in SWW for ten days were recorded using ATR-FTIR spectroscopy (JASCO FT/IR-6300, Japan), with a diamondenabled ATR sample holder and a DLaTGS detector in the spectral range of 400 to $4,000 \mathrm{~cm}^{-1}$. The functional components in the samples were identified qualitatively by matching the maximum peak hit ( $>99.5$ peak region matching) with the IR Spectral Library using the KnowItAll software (BioRad Laboratories, Munchen, Germany). The analysis of the second derivative spectra (2800-3050 $\mathrm{cm}^{-1}$ and $1350-1500 \mathrm{~cm}^{-1}$ ) was done by the Means-Movement method (smoothing with a convolution width of 25) using the Jasco Spectra Manager software. All analyses were done thrice to confirm the reproducibility of the data.

\section{Principle component analysis of FTIR data}

Principal component analysis (PCA) was independently performed on two ranges, $3050-2800 \mathrm{~cm}^{-1}$ and $1500-$ $1350 \mathrm{~cm}^{-1}$, to evaluate the changes in the fatty acid composition during the fungal growth in the XLSTAT version 6.0 software [37]. Since each range provides diverse and specific information, splitting the analysis into different ranges allows an easier interpretation of the PCA results. Further, it was compared with an individual fatty acid standard such as palmitic, stearic, oleic, and linoleic acid (Sigma-Aldrich, St Louis, MO, USA). The correlation matrix was computed on standardized spectra (zero mean and standard deviation equal to 1) and diagonalized to get eigenvectors (loadings, v) sorted according to the magnitude of the corresponding eigenvalues [38]. In all cases, the first three eigenvectors already described were more than $95 \%$ of the total variance of the data. The principal components (scores) were obtained by projecting the original spectra on the orthogonal subspace defined by the first three eigenvalues.

\section{Fatty acid profiling of $A$. caespitosus ASEF 14 by GC-FID}

To evaluate the potential utilities of fungal oil from superior lipid-yielding oleaginous fungus $A$. caespitosus ASEF14 grown in SWW as a biodiesel feedstock, its fatty acid profile was determined by gas chromatography method (GC-FID). To emphasize the nutrient effect on the FAME profile, the biomass of fungus grown from SM was also processed. For this analysis, $100 \mathrm{mg}$ of biomass obtained at periodic intervals from both SM and SWW samples were separately added to a mixture of $10 \mathrm{~mL}$ of methanolic-sulfuric acid $(0.1 \%$ sulfuric acid in methanol), followed by vigorous mixing. In this mixture, $10 \mathrm{~mL}$ of chloroform was added, and the resultant mixture was heated to $80{ }^{\circ} \mathrm{C}$ for $2 \mathrm{~h}$. Subsequently, the samples were removed and cooled to ambient temperature. Distilled water $(1 \mathrm{~mL})$ was added, and the suspension was centrifuged at 1,500 rpm for $5 \mathrm{~min}$. The lower aqueous phases containing the FAME were analyzed in a gas chromatography system (Perkin Elmer Clarus 680, US) coupled with a flame ionization detector (FID) using an Elite-5 column (30 m $\times 0.25 \mathrm{~mm}, 0.25 \mu \mathrm{m}$ film thickness). The injection temperature was $220{ }^{\circ} \mathrm{C}$, and the initial column temperature was $160{ }^{\circ} \mathrm{C}$. The final temperature of $190{ }^{\circ} \mathrm{C}$ was achieved by increasing the temperature at a rate of $3{ }^{\circ} \mathrm{C}$ per min, and the detector temperature was $270{ }^{\circ} \mathrm{C}$. Helium was used as the carrier gas at a flow rate of $1.3 \mathrm{~mL} \mathrm{~min}{ }^{-1}$. The FAME composition of the fungal oil was determined by comparing the retention time and the peak area of the samples with the FAME mix (SigmaAldrich, St Louis, MO, USA) [14].

\section{FAME composition\%}

$$
=\frac{\frac{\text { Standard conc. }}{\text { Standardarea }} \times \frac{\text { Sample area }}{\text { Samplewt }(m g)} \times \text { Dilution factor }}{10000}
$$




\section{Fuel properties of fungal biodiesel}

The fuel and quality criteria of biodiesel are strongly influenced by the chemical structure (chain length and number of double bonds) of fatty acids present in the lipid feedstock [39]. We used the predictive model equations to evaluate biodiesel fuel properties based on their fatty acid composition. To evaluate the fuel properties of SWW-grown A. caespitosus ASEF14, key physicochemical fuel properties, including density $(\rho)$, kinematic viscosity (KV), saponification value (SV), iodine value (IV), higher heating value (HHV), oxidative stability (OS), cetane number $(\mathrm{CN})$, long-chain saturated factor (LCSF), cold filter plugging point (CFPP), cloud point $(\mathrm{CP})$, pour point (PP), and degree of unsaturation (DU), were estimated. The equations given below were used to estimate the various properties of fungal biodiesel from the FAME profile.

Kinematic viscosity $\left(v, \mathrm{~mm}^{2} \mathrm{~s}^{-1}\right)$ at $40{ }^{\circ} \mathrm{C}$, density $(\rho, g$ $\mathrm{cm}^{-3}$ ) at $20^{\circ} \mathrm{C}$, and $\mathrm{HHV}$ of the biodiesel were estimated using the following equation [40]

$$
\begin{aligned}
& \ln (v)=\sum_{\left.-0.178 \times \mathrm{D}_{\mathrm{i}}\right)} \mathrm{N}_{\mathrm{i}}\left(-12.503+\left(2.496 \times \ln \mathrm{Mw}_{\mathrm{i}}\right)\right. \\
& \rho=\sum \mathrm{N}_{\mathrm{i}}\left(0.8463+\left(4.9 / \mathrm{Mw}_{\mathrm{i}}\right)+0.0118 \times \mathrm{D}_{\mathrm{i}}\right) \\
& \mathrm{HHV}=\sum \mathrm{N}_{\mathrm{i}}\left(46.19-\left(1794 / \mathrm{Mw}_{\mathrm{i}}\right)-0.21 \times \mathrm{D}_{\mathrm{i}}\right)
\end{aligned}
$$

Here, $\mathrm{Mw}_{\mathrm{i}}$ is the molecular weight of a fatty acid, $\mathrm{N}_{\mathrm{i}}$ is the percentage of the given fatty acid in the biodiesel, and $D_{i}$ is the number of double bonds in the given fatty acid.

The saponification value (SV), iodine value (IV), and cetane number $(\mathrm{CN})$ [41] were calculated using the following equations:

$$
\begin{aligned}
& \mathrm{SV}=\sum(560 \times \mathrm{N}) / \mathrm{M} \\
& \mathrm{IV}=\sum(254 \times \mathrm{D} \mathrm{N}) / \mathrm{M} \\
& \mathrm{CN}=46.3+(5.458 / \mathrm{SV})-(0.225 \times \mathrm{IV})
\end{aligned}
$$

where $\mathrm{D}=$ number of double bonds in the fatty ester, $\mathrm{M}=$ molecular mass of fatty ester, and $\mathrm{N}=$ percentage of the particular fatty ester in oil sample. The degree of unsaturation (DU) and oxidative stability (OS) [42] were calculated as follows:

$$
\begin{aligned}
& \mathrm{DU}=\mathrm{MUFA}+(2 \times \text { PUFA }) \\
& \mathrm{OS}=117.9295 /\left(\mathrm{wt} \% \mathrm{C}_{18: 2}+\mathrm{wt} \% \mathrm{C}_{18: 3}+2.5905\right)
\end{aligned}
$$

where $M U F A=$ monounsaturated fatty acid and PUFA $=$ polyunsaturated fatty acid.

The LCSF, CFPP, CP [43], and PP [44] were estimated as follows:

$$
\begin{aligned}
& \begin{array}{c}
\mathrm{LCSF}=\left(0.1 \times \mathrm{C}_{16}\right)+\left(0.5 \times \mathrm{C}_{18}\right)+\left(1 \times \mathrm{C}_{20}\right) \\
\quad+\left(1.5 \times \mathrm{C}_{22}\right)+\left(2 \times \mathrm{C}_{24}\right)
\end{array} \\
& \mathrm{CFPP}=(3.1417 \times \mathrm{LCSF})-16.477 \\
& \mathrm{CP}=\left(0.526 \times \mathrm{C}_{16}\right)-4.992 \\
& \mathrm{PP}=\left(0.571 \times \mathrm{C}_{16}\right)-12.24
\end{aligned}
$$

\section{Decontamination study}

After kinetic fermentation, the treated/spent wastewater was filtered and used to estimate the physicochemical parameters, similar to raw wastewater. The percentage reduction was calculated and compared.

\section{Statistical analysis}

All experiments were performed in triplicate. Data are presented as mean \pm standard deviation $(n=3)$. The statistical significance between the samples was evaluated using one-way ANOVA (analysis of variance) $(p<0.05)$ in the XLSTAT version 6.0 software.

\section{Results and discussion}

Significant amounts of starch are present in tapioca tubers. Its industrial processing generates enormous wastewater that is rich in organic loads and starch. Therefore, it is highly important to explore such wastewater as a substrate for lipid production by oleaginous fungi. Hence, we isolated starch-utilizing fungi having a high lipid-accumulating ability, which could be used for biodiesel production and simultaneous decontamination of starch-rich wastewater.

\section{Isolation and screening of fungal isolates for amylase activity}

Fifteen fungal isolates (ASEF1, ASEF2, ASEF4, ASEF7, ASEF8, ASEF9, ASEF10, ASEF12, ASEF13, ASEF14, ASEF15, ASEF17, ASEF19, ASEF20, and ASEF23) with the different visible colony and cell morphology (as observed under the microscope) were obtained from the enriched SWW sample. Amylase is the primary enzyme responsible for starch hydrolysis. It is reported that when complex carbon sources are used for 
microbial lipid production, the capability of oleaginous fungi to secrete amylase is critical to obtain high lipid yields $[45,46]$. As SWW is rich in starch, screening the fungal isolates for amylase activity would be a prerequisite for assessing their ability to efficiently grow and produce lipids [47]. Hence, the selected isolates were screened for amylase production using the starch plate method, resulting in a clear zone of starch hydrolysis in the Petri dishes after iodine treatment. Among them, six fungal isolates were found to be positive for amylase production, as determined by measuring the width of the clear zone (zone of hydrolysis) formed around the fungal colonies on starch agar medium, and its width ranged from 8 to $35 \mathrm{~mm}$ (Fig. 2a). The (a)

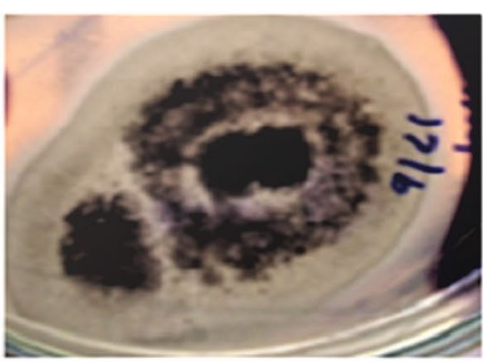

ASEF 1

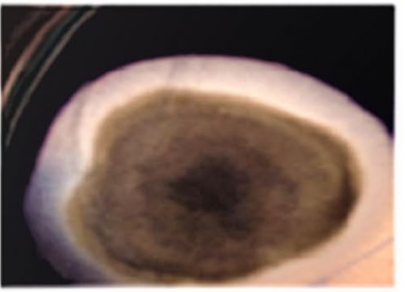

ASEF18

(b)

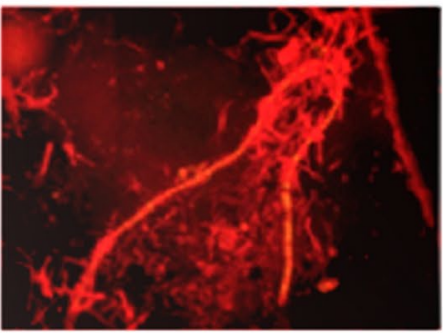

ASEF 1

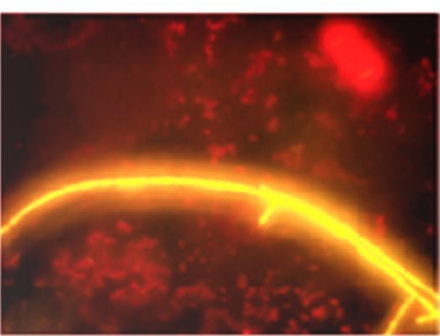

ASEF18

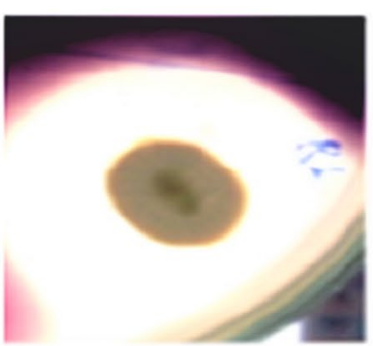

ASEF14

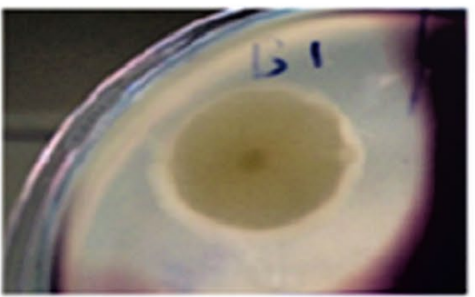

ASEF24

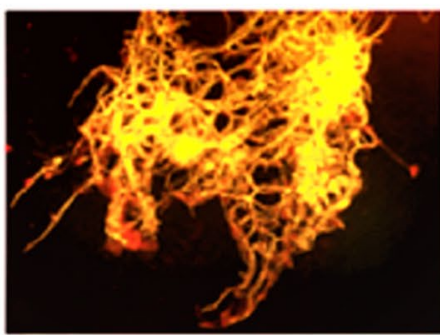

ASEF14

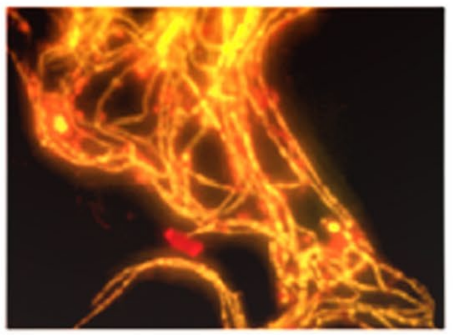

ASEF24

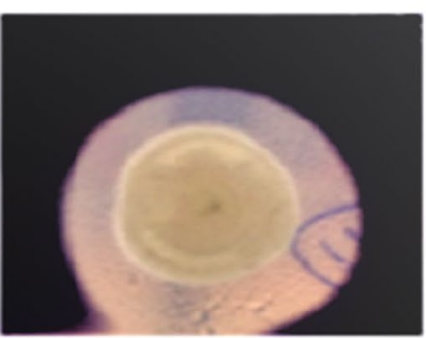

ASEF17

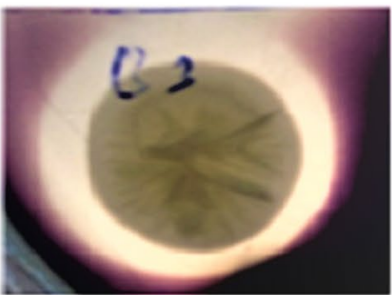

ASEF25

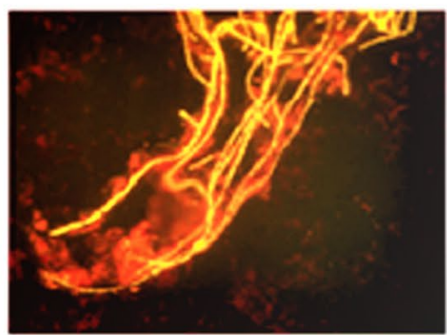

ASEF 17

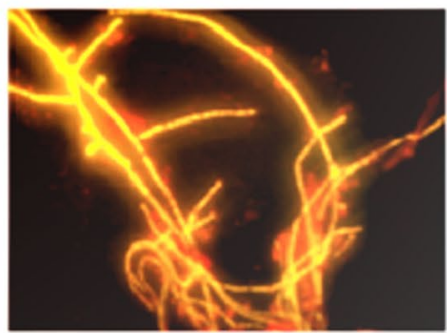

ASEF25

Fig. 2 a Amylase-positive isolates showing a clear zone around the colony on starch agar. $\mathbf{b}$ Nile red-stained lipid bodies of selected fungal isolates 
fungal isolate ASEF14 produced the maximum zone of hydrolysis, i.e., $35 \mathrm{~mm}$, followed by ASEF24 (30 mm) and fungal isolate ASEF1 produced a minimum zone of $8 \mathrm{~mm}$ (Fig. 2a). These isolates were selected for further screening of oleaginicity by NR staining. Quantitative amylase assay revealed the maximum amylase activity of $48.03 \mathrm{IU} \mathrm{mL} \mathrm{mL}^{-1}$ for the fungal isolate ASEF14.

\section{Nile red staining}

High levels of lipid accumulation were observed in oleaginous fungi when carbon was available in excess, whereas critical nutrients such as nitrogen or phosphorus were limited [48]. These accumulated lipids or single-cell oils (SCO) are deposited as intracellular LBs. NR, a fluorescent lipophilic probe, was used to stain and detect LBs in intact cells [49]. This dye has great advantages over other dyes due to its fluorescence emission spectrum, which differs according to the type of lipid. Lipid detection by NR has been commonly measured with excitation at 480 to $490 \mathrm{~nm}$ and 510 to $560 \mathrm{~nm}$. The former target neutral lipids showed yellow emission, and the latter target polar lipids showed red or orange emission [50]. Such differentiation enabled the efficient use of NR to select microorganisms that accumulated lipids of interest for biodiesel production. The yellow emission was observed throughout the fungal hyphae of ASEF14, ASEF17, ASEF18, ASEF24, and ASEF25 isolates, which confirmed their oleaginicity and the presence of neutral lipids (Fig. 2b). In contrast, a faint or no fluorescence signal was detected in the case of non-oleaginous fungal isolate ASEF1 (Fig. 2b), while in control, red color was seen. Kimura et al. [28] visualized the LBs of several oleaginous fungi, namely, Lipomyces starkeyi IFO-10381, Rhodosporidium toruloides IFO-0559, Cryptococcus curvatus IFO-1159, and Mortierella isabellina IFO-7884 that varied in size, number, and shape [28].

\section{Biomass and lipid yields (SCOs)}

The application of oleaginous microorganisms for oil production necessitates the use of strains with high lipid-accumulation capability. All six fungi grew well in a carbon-rich, nitrogen-limiting medium for up to seven days [45]. They significantly differed in their biomass yield, lipid yield, and lipid content. All fungal cultures produced good biomass with the dry cell weight (DCW) ranging from 4.10 to $9.01 \mathrm{~g} \mathrm{~L}^{-1}$. The total lipid from all fungal cell mass was extracted and estimated (Table 1). The fungal isolates varied in their lipid yield; the ASEF14 culture produced the maximum lipid yield of $3.31 \mathrm{~g} \mathrm{~L}^{-1}$. Among the six fungi, three were found to be oleaginous as the total lipid contents were more than 20\%, with the highest lipid content of $54.6 \%$ for ASEF14, followed by $28.51 \%$ for ASEF25 in SM. The results of the present
Table 1 Microbial lipid production by selected fungal isolates

\begin{tabular}{llll}
\hline Isolates & $\begin{array}{l}\text { Biomass yield } \\
\left(\mathbf{g ~ L}^{-1}\right)\end{array}$ & $\begin{array}{l}\text { Lipid yield } \\
\left(\mathbf{g ~ L}^{-1}\right)\end{array}$ & Lipid content (\%) \\
\hline ASEF1 & $6.66( \pm 1.0)^{\mathrm{b}}$ & $1.04( \pm 0.1)^{\mathrm{c}}$ & $16.29( \pm 4.0)^{\mathrm{bc}}$ \\
ASEF14 & $6.06( \pm 0.0)^{\mathrm{bc}}$ & $3.31( \pm 0.3)^{\mathrm{a}}$ & $54.6( \pm 5.0)^{\mathrm{a}}$ \\
ASEF18 & $9.01( \pm 1.0)^{\mathrm{a}}$ & $1.60( \pm 0.0)^{\mathrm{b}}$ & $17.97( \pm 2.0)^{\mathrm{bc}}$ \\
ASEF17 & $4.10( \pm 0.4)^{\mathrm{c}}$ & $0.95( \pm 0.0)^{\mathrm{c}}$ & $23.29( \pm 1.3)^{\mathrm{bc}}$ \\
ASEF24 & $4.73( \pm 0.0)^{\mathrm{bc}}$ & $0.67( \pm 0.1)^{\mathrm{c}}$ & $14.16( \pm 2.1)^{\mathrm{c}}$ \\
ASEF25 & $5.33( \pm 0.2)^{\mathrm{bc}}$ & $1.52( \pm 0.0)^{\mathrm{b}}$ & $28.58( \pm 1.8)^{\mathrm{b}}$ \\
\hline
\end{tabular}

study are similar to those of previous reports that stated, the lipid-producing potential of fungi such as Alternaria alternata (40.7\% lipid content per dry mass), Cladosporium cladosporioides (38.5\%), Epicoccum nigrum (38\%), Fusarium oxysporum (32\%), Aspergillus parasiticus (28.2\%), Emericella nidulans var. lata (24.5\%), Mucor circinelloides MU241 (23\%), Aspergillus sp. (23.3\%), and Schizochytrium sp. LU310 (49\%-67\%) [29, 47, 51, 52].

\section{Identification of superior lipid-yielding fungal isolate (ASEF14)}

The total DNA of the maximum lipid-producing fungus ASEF14 was isolated. The ITS region of the isolate was PCR amplified using ITS1 and ITS4 primers [53]. The PCR product showed an amplicon band size of $600 \mathrm{bp}$. The analysis of the ASEF14 sequence using BLAST showed $100 \%$ similarity with $A$. caespitosus. The $28 \mathrm{~S}$ rRNA gene sequence data of the above strain is available in the NCBI database with accession no. MF599090. Phylogenetic analysis using the neighbor-joining method positioned and clustered the fungus strain with corresponding sequence-matching genomes (Fig. 3).

Understanding the mechanisms driving lipogenesis could have a major impact on the future use of SCOs as biodiesels. The information available on lipid metabolism in Aspergillus spp. at the cellular level is very limited. In 2012, Vorapreeda et al. [54] compared the genomes of non-oleaginous (Saccharomyces cerevisiae, Candida albicans, and Ashbya gossypii) and oleaginous strains (Yarrowia lipolytica, Rhizopus oryzae, Aspergillus oryzae, and Mucor circinelloides) and discovered 209 orthologous protein sequences; of these, 41 sequences were involved in the production of acetyl-CoA, a precursor for fatty acid and lipid synthesis, but they were absent in non-oleaginous strains. It was also suggested that there exists a link between carbohydrate, lipid, and amino acid metabolism.

Thammarongtham et al. [55] reported the genome sequence of the oleaginous $A$. oryzae BCC7051. They compared the structural genes focusing on the involvement in lipid metabolism among oleaginous yeast and fungi, which revealed the presence of multiple isoforms 


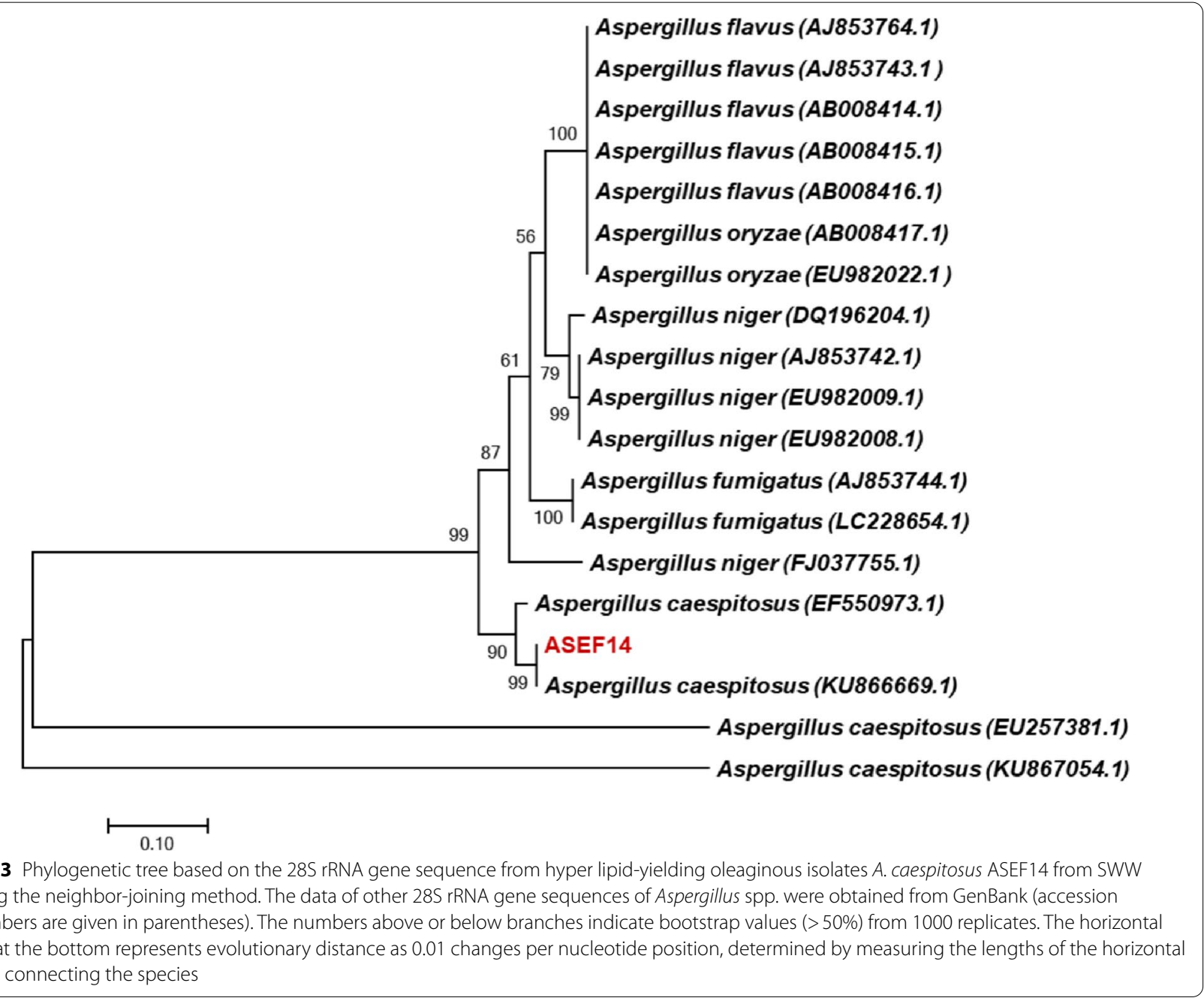

of metabolic enzymes responsible for fatty acid synthesis. They also found alternative routes of acetyl-CoA generation and malate/citrate/pyruvate shuttle as oleaginous features. This shuttle mechanism appears to be universal in eukaryotes $[56,57]$, but the exact metabolic network of this shuttle is species-specific. The analysis of the genomic data aids in comprehending the species' distinctive characteristics for high-level lipid accumulation, suggesting the Aspergillus genome could be a potential candidate for biodiesel production.

\section{Growth and lipid production kinetics of $A$. caespitosus ASEF14 grown in SM and SWW}

A. caespitosus ASEF14 was grown in SM and SWW with a C:N ratio of 30:1 for ten days. The samples were withdrawn at every $24 \mathrm{~h}$ interval for up to ten days. In SM, the fungus produced the maximum biomass of $6.93 \mathrm{~g} \mathrm{~L}^{-1}$ on the $10^{\text {th }}$ day, with a lipid yield of $2.35 \mathrm{~g} \mathrm{~L}^{-1}$ and the highest starch utilization of about $23.07 \mathrm{~g} \mathrm{~L}^{-1}$. However, the maximum lipid yield of $3.50 \mathrm{~g} \mathrm{~L}^{-1}$ was observed on the sixth day, with starch utilization of about $16.01 \mathrm{~g} \mathrm{~L}^{-1}$ (Fig. 4a). The maximum amylase activity of $48 \mathrm{IU} \mathrm{mL} \mathrm{m}^{-1}$ was observed on the seventh day; however, after the eighth, ninth, and tenth days of incubation, only little variability was observed in the values (Fig. 4a).

In SWW, the fungus attained the maximum biomass of $4.73 \mathrm{~g} \mathrm{~L}^{-1}$ on the $10^{\text {th }}$ day, with a lipid yield of $1.23 \mathrm{~g} \mathrm{~L}^{-1}$. Nevertheless the fungus produced the maximum lipid yield of $1.39 \mathrm{~g} \mathrm{~L}^{-1}$ and lipid content of $37.27 \%$ on the seventh day. Afterward, the lipid yield and content declined gradually. The lipid content of more than $30 \%$ was recorded on sixth $(33.5 \%)$, seventh $(37.27 \%)$, and eighth days $(35.37 \%)$. The amylase secretion gradually increased from the first day onwards and attained the maximum value on the $10^{\text {th }}$ day $\left(26.51 \mathrm{IU} \mathrm{mL}^{-1}\right)$. The residual starch level at the end of fermentation was $11.12 \mathrm{~g} \mathrm{~L}^{-1}$. The kinetic analyses of $A$. caespitosus ASEF14 grown in SWW are presented in Fig. $4 \mathrm{~b}$. 


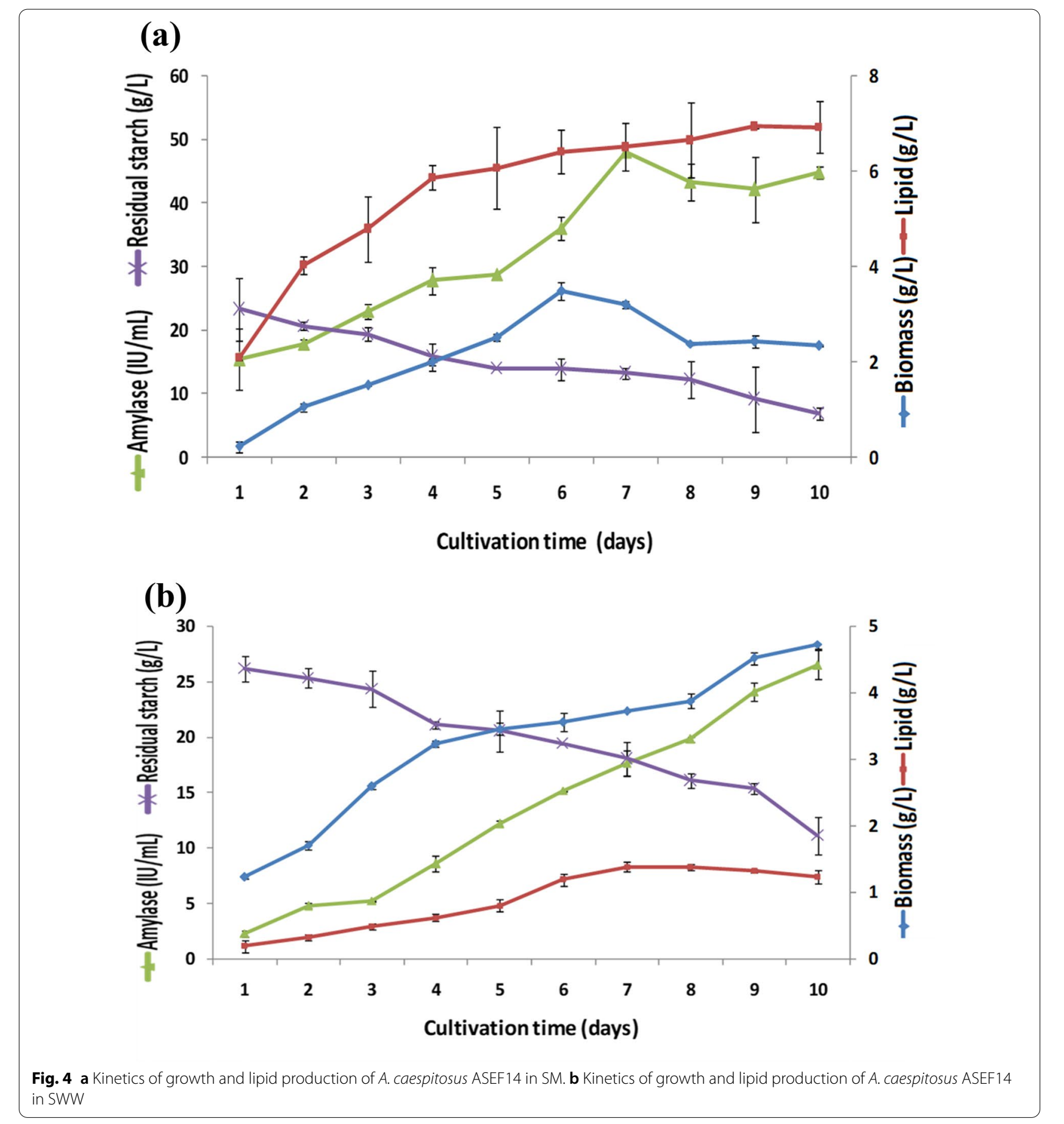

The lipid yield reported in this study seems to be promising in the cost-effective production of lipids from SWW, and there is plenty of scope for improvement by optimizing the nutritional and growth conditions. The lipid content of ASEF14 was found to be around $37.27 \%$, which is consistent with the following findings. The oleaginous yeast $R$. glutinis cultured on corn starch wastewater supplemented with waste syrup has a lipid content of $35 \%$, according to Xue et al. [58]. Muniraj et al. [13] reported that oleaginous fungus grown on PPW produced a lipid content of $40 \%$.

The conversion rate or $\mathrm{Y}_{\mathrm{L} / \mathrm{C}}$ ( $\mathrm{g}$ of lipid produced per $\mathrm{g}$ of substrate consumed) in SM by A. caespitosus ASEF14 was found to be 0.03 to $0.22 \mathrm{~g}$ of lipid per gram of starch 
consumed. The maximum $\mathrm{Y}_{\mathrm{L} / \mathrm{C}}$ value of $0.22 \mathrm{~g} \mathrm{~g}^{-1}$ was obtained on day 6 of fermentation. In SWW, $\mathrm{Y}_{\mathrm{L} / \mathrm{C}}$ values ranged from 0.05 to $0.12 \mathrm{~g} \mathrm{~g}^{-1}$ of starch consumed. When microalgae Schizochytrium limacinum was grown on biodiesel-derived glycerol, a similar lipid yield of $0.15 \mathrm{~g}$ lipids per gram of glycerol was produced [59]. Cunninghamella echinulata ATHUM 4411, an oleaginous fungus, converted a gram of starch into 0.15 g lipids when cultivated on pure starch [45]. Muniraj et al. [13] found that A. oryzae cultured in PPW yielded $0.11-0.16$ g lipids per gram of soluble starch. In our prior investigation, the oleaginous yeast Candida tropicalis ASY2 produced 0.079$0.135 \mathrm{~g}$ of lipid per gram of starch consumed [14]. This is noteworthy because the lipid yield on glucose consumption can seldom exceed 0.22 g lipids per gram of glucose under optimal circumstances for SCO synthesis [60]. Hence, the lipid accumulation potential of the studied oleaginous fungi seems to be much better.

The amylolytic potential of fungus was directly associated with the $\mathrm{Y}_{\mathrm{L} / \mathrm{C}}$ values. The high amylase enzyme secretion by fungi in the SM $\left(48 \mathrm{IU} \mathrm{mL} \mathrm{m}^{-1}\right)$ boosted substrate utilization by two-fold $\left(\mathrm{Y}_{\mathrm{L} / \mathrm{C}}: 0.22 \mathrm{~g} \mathrm{~g}^{-1}\right)$ compared to SWW (26.51 IU $\left.\mathrm{mL}^{-1} ; 0.12 \mathrm{~g} \mathrm{~g}^{-1}\right)$. The higher substrate conversion seen in SM could be attributed to the existence of a more easily degradable substrate (soluble starch). In SWW, the substrate was available either in aggregated/complex (waste solids) or dissolved form.

Fungi produce enzymes that are specific to the substrates that aid in the breakdown of complex molecules into simple forms, and it is used as a metabolic form. A filamentous fungus Aspergillus capable of producing glucoamylases, pectinases, and galactosidases from complex molecules [46]. In the present study, we also confirmed that the amylolytic potential of oleaginous fungi is linked to the consumption of its relevant substrate starch. This promotes chemo-heterotrophic fungal nutrition, resulting in increased growth and lipid accumulation.

\section{FTIR analysis of lipid profile change in oleaginous fungi during lipid accumulation}

The spectra collected from cells are in their natural state and are considered to be a molecular "fingerprint" of the total chemical composition of cells. As a result, they form a distinct fingerprint of cell lipids, proteins, nucleic acids, and carbohydrates $[61,62]$. In the present study, the changes in the lipid profile of $A$. caespitosus ASEF14 from day 1 to day 10 grown in SWW were investigated using FTIR spectroscopy (Fig. 5). Table 2 lists the assigned FTIR spectral bands and their corresponding functional groups.

In these infrared spectra, cellular lipids were represented by several peaks, related to different lipid functional groups: (i) peaks in the regions $3050-2800 \mathrm{~cm}^{-1}$ (peaks: $1-3$ in Fig. 5), (ii) $1500-1300 \mathrm{~cm}^{-1}$ (peaks: 6-9), and (iii) at $725 \mathrm{~cm}^{-1}$ (peak: 10) are related to lipid acyl chains. In detail, the absence of peaks from 4000 to $3010 \mathrm{~cm}^{-1}$ region in the extracted lipid indicated the absence of a free hydroxyl group $(-\mathrm{OH})$ and an amine group $\left(-\mathrm{NH}_{2}\right)$. The peak around $3008 \mathrm{~cm}^{-1}$ (peak: 1 ) corresponds to $=\mathrm{C}-\mathrm{H}$ stretching and indicates lipid unsaturation index of lipids and oils [63]. In the fatty acids of TAGs, peak at $2955 \mathrm{~cm}^{-1}$ and $1380 \mathrm{~cm}^{-1}$ representing $\mathrm{CH}_{3}$ stretching of acyl chains; peaks at $2925 \mathrm{~cm}^{-1}$, $2850 \mathrm{~cm}^{-1}$, and $725 \mathrm{~cm}^{-1}$ representing $\mathrm{CH}_{2}$ stretching of acyl chains (Fig. 5). The other important peak for the lipid analysis occurs in the lower wavenumber region at $1745 \mathrm{~cm}^{-1}$ (peak: 5), which is related to the ester carbonyl bond from lipid triglycerides and fatty acids, which represents the majority of the total lipid content in the cell $[4,63]$.

In detail, when comparing the spectra of $A$. caespitosus ASEF14 from day 1 to day 10, we observed significant differences, owing to the accumulation of lipids. Indeed, the intensity of the $\mathrm{CH}$ stretching bands spanning around 3050 and $2800 \mathrm{~cm}^{-1}$ increased until the middle of the fermentation days (days 1-7), then began to decline slightly. It may be due to stress response or lipid turnover. On day 2 , the existence of unsaturated fatty acids is due to the olefinic group $=\mathrm{CH}$ at $3010 \mathrm{~cm}^{-1}$ in the IR spectrum.

From day 2 onward, the strength of the ester carbonyl band about $1740 \mathrm{~cm}^{-1}$ increased dramatically. Overall, these findings confirmed the intensification of all lipidrelated bands in mid-IR spectra of $A$. caespitosus ASEF14 with the cultivation time leading to major biochemical changes in the fungus that were related to intracellular lipid accumulation.

\section{Second derivative analysis of the FTIR fungal spectra in lipid region}

We studied the second derivatives of the FTIR absorption spectra to understand better the spectral changes in the lipid component that occurs throughout the growth phase because it enabled resolving the overlapping components of IR absorption bands [4]. In particular, we compared the second derivative spectra of extracted lipid from day 1 to day 6 and 7, when the oleaginous fungi had stored a significant amount of FA. Figure 6a shows the second derivative spectra in the range of 3050 to $2800 \mathrm{~cm}^{-1}$, which is dominated by lipid acyl chain absorption. As shown in Fig. 6a, the spectrum on day 1 is characterized mainly by four bands at approximately $2960 \mathrm{~cm}^{-1}\left(v_{\text {asym }} \mathrm{CH}_{3}\right), 2922 \mathrm{~cm}^{-1}$ $\left(v_{\text {antisym }} \mathrm{CH}_{2}\right), 2872 \mathrm{~cm}^{-1}\left(v_{\text {sym }} \mathrm{CH}_{3}\right)$, and $2852 \mathrm{~cm}^{-1}$ $\left(v_{\text {sym }} \mathrm{CH}_{2}\right)$. These spectral features changed dramatically on days 6 and 7; in particular, the intensity of 


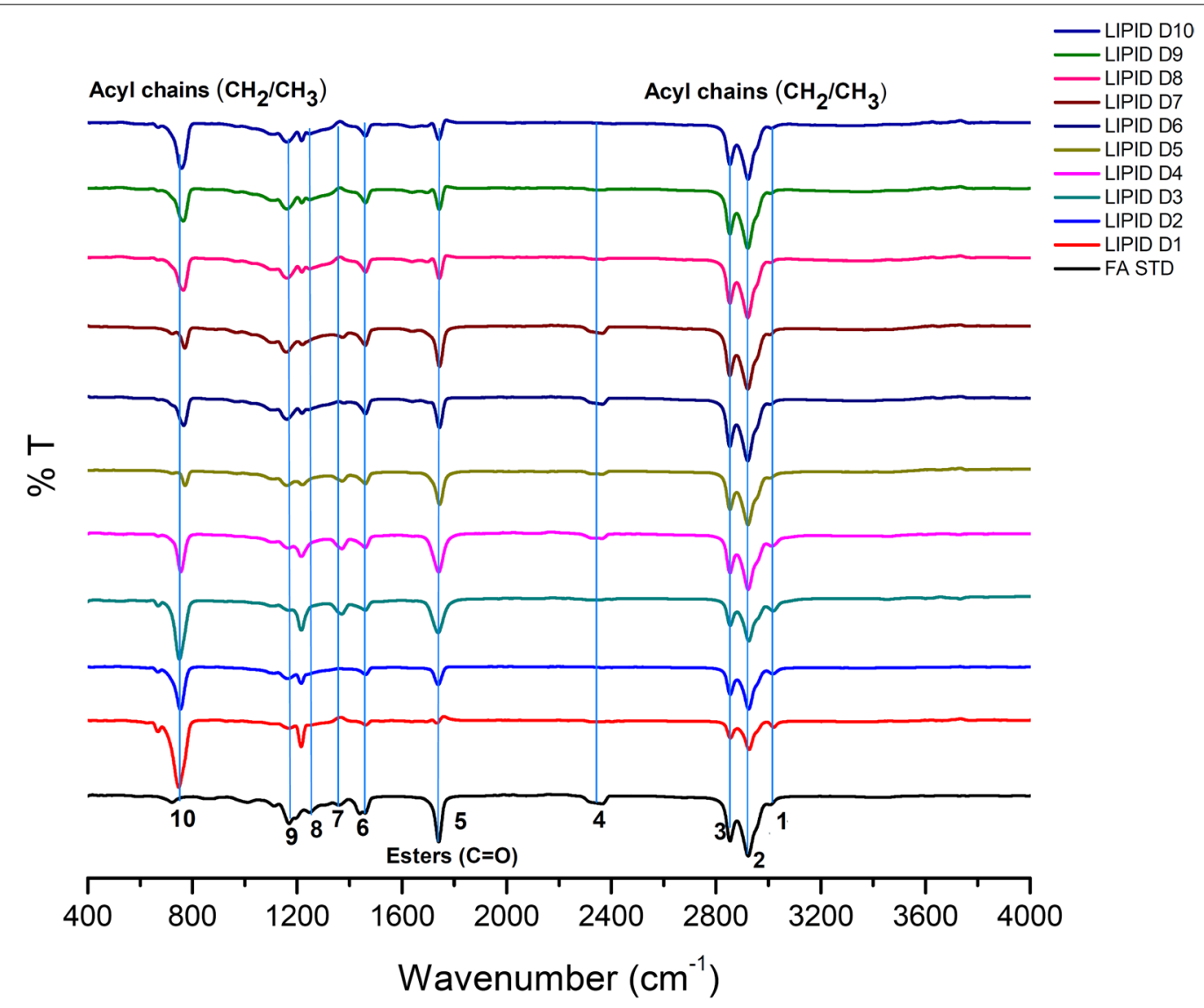

Fig. 5 Fourier transform infrared (FTIR) analysis of A. caespitosus ASEF14 lipid samples derived from day 1 to 10 grown in SWW. The most important lipid molecule absorption peaks are indicated (1-10)

Table 2 Peaks assignment in the FTIR spectra of microbial lipid (lipid characteristics)

\begin{tabular}{|c|c|c|c|c|}
\hline Peak No & Wavenumber $\left(\mathrm{cm}^{-1}\right)$ & Peak assignment & Representing biomolecule & References \\
\hline 1 & 3008 & $=\mathrm{C}-\mathrm{H}$ stretching & Lipid & {$[85,86]$} \\
\hline 2 & 2953 & $-\mathrm{C}-\mathrm{H}\left(\mathrm{CH}_{3}\right)$ stretching (asym) & Lipid & \\
\hline 3 & 2924 & $-\mathrm{C}-\mathrm{H}\left(\mathrm{CH}_{2}\right)$ stretching (asym) & Lipid & \\
\hline 4 & 2853 & $-\mathrm{C}-\mathrm{H}\left(\mathrm{CH}_{2}\right)$ stretching (sym) & Lipid & \\
\hline 5 & 1745 & $-\mathrm{C}=\mathrm{O}$ (ester) stretching & Lipid & \\
\hline 6 & 1465 & $-\mathrm{C}-\mathrm{H}\left(\mathrm{CH}_{2}, \mathrm{CH}_{3}\right)$ bending (scissoring) & Lipid & \\
\hline 7 & 1415 & $\mathrm{C}-\mathrm{H}$ rocking & Protein & [87] \\
\hline 8 & 1377 & $-\mathrm{C}-\mathrm{H}\left(\mathrm{CH}_{3}\right)$ bending (sym) & Lipid & {$[86]$} \\
\hline 9 & $1240-1265$ & $\begin{array}{l}\mathrm{P}=\mathrm{O} \text { asymmetric stretching of }>\mathrm{PO}_{2} \text { phos- } \\
\text { phodiester }\end{array}$ & Polyphosphate, phospholipid & \\
\hline 10 & 720 & $\mathrm{CH}_{2}$ rocking, bending & Lipid & \\
\hline
\end{tabular}

the acyl chain bands increased. Furthermore, due to the $=\mathrm{CH}$ stretching mode, which is typical of unsaturated fatty acids, a well-resolved component was nearly non-existent on day 1 and appeared at $3009 \mathrm{~cm}^{-1}$ on days 6 and 7. Overall, these findings suggested that the lipid content changed significantly during their growth, likely reflecting the accumulation of fatty acids at high levels, including unsaturated ones.

The absorption between 1500 and $1350 \mathrm{~cm}^{-1}$ (see Fig. 6b) was subsequently investigated, because this is where other vibrational modes related to lipid $\mathrm{CH}_{2}$ and $\mathrm{CH}_{3}$ occur. In particular, the second derivative 

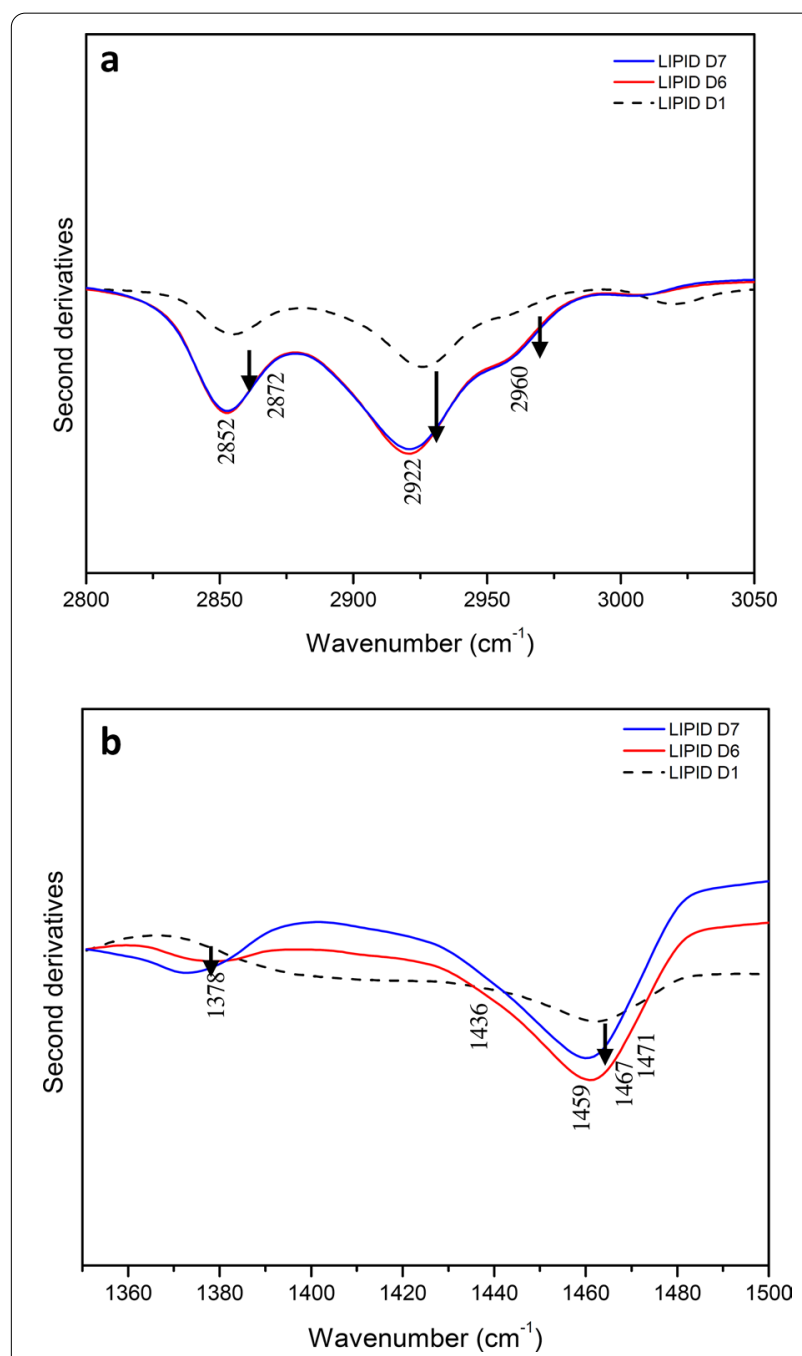

Fig. 6 Second derivative analyses of A. caespitosus ASEF14 lipid samples. a The second derivative spectra are reported between 3050 and $2800 \mathrm{~cm}^{-1}$ wavelength range and $\mathbf{b} 1500-1350 \mathrm{~cm}^{-1}$, after normalization. The arrows represent increasing intensities

spectrum of $A$. caespitosus ASEF14 on day 1 was characterized by well-resolved components around $1471 \mathrm{~cm}^{-1}$ (acyl chain $\mathrm{CH}_{2}$ bending and/or $\mathrm{CH}_{3}$ deformation), $1459 \mathrm{~cm}^{-1}$ and $1436 \mathrm{~cm}^{-1}\left(\mathrm{CH}_{3}\right.$ deformation) $[64,65]$. On days 6 and 7, new well-resolved components attributable to $\mathrm{CH}_{3}$ bending vibrations appeared at $1378 \mathrm{~cm}^{-1}$, in addition to a significant rise in the intensity of the $1467 \mathrm{~cm}^{-1}$ band [66]. These spectral fluctuations indicate changes in the metabolism associated with lipid synthesis during growth. FTIR spectroscopy can reveal small variations in cultivation parameters such as variations in culture time, medium composition, $\mathrm{pH}$, temperature, water content or culture storage conditions $[62,67]$.
Ami et al. [4] used FTIR for the comparison of lipid accumulation of two oleaginous yeasts and the non-oleaginous species Saccharomyces cerevisiae. Deeba et al. [68] monitored the lipid profile of oleaginous yeasts by FTIR for extracted lipid samples. Signori et al. [69] monitored the lipid accumulation from crude glycerol over the fermentation time in different oleaginous yeasts. Shapaval et al. [70] characterized the total biochemical profile of oleaginous yeasts, which enabled us to identify strains and substrate(s) providing the highest total lipid content using FTIR spectroscopy. In the present study, FTIR spectroscopy successfully demonstrated the lipid accumulation pattern over the fermentation time in oleaginous fungi $A$. caespitosus ASEF14 from SWW.

\section{FTIR spectroscopy coupled with principal component analysis (PCA) for monitoring lipid accumulation}

In order to determine the spectroscopic changes observed in specific lipid molecules during the growth of $A$. caespitosus ASEF14, their IR responses were compared with selected fatty acid standards, which included saturated (palmitic and stearic acid), monounsaturated (oleic), and polyunsaturated (linoleic) ones. We performed PCA for the lipid samples taken from day 1 to day 10 of $A$. caespitosus ASEF14 in two wavelength ranges, namely 3050 and $2800 \mathrm{~cm}^{-1}$ (Fig. 7) and 1500 and $1350 \mathrm{~cm}^{-1}$ (Fig. 8). The initial spectral range is predominated by the lipid acyl chain absorption, and the latter one is dominated by several vibrational modes due to both lipid acyl chains and head groups.

The PCA of the assessed variables in the range of $2800-3050 \mathrm{~cm}^{-1}$ showed that the first and second components explain $96.88 \%$ of the total variance among different incubation days. Of which, PC1 contributes $82.71 \%$, while PC2 adds another $14-17 \%$ (Fig. 7a). The bi-plots describing the orthogonal positions of variables explained by the first two PCs are presented in Fig. 7a. In particular, looking at the PCA score plots, we observed that lipid samples derived from days 1 and 5 were plotted in the F3 along with individual standard fatty acids, namely oleic and linoleic, but days 6 to 10 samples were plotted in F4. This may be due to shorter vector length than the other day variables. In the samples of all studied days, oleic and linoleic standard fatty acids were positively correlated with each other (narrow angled) due to unsaturation represented by $\mathrm{CH}_{2}\left(v_{\text {sym }}\right)$ and $=\mathrm{CH}$, likely reflecting a higher amount of unsaturated fatty acids accumulation. The standards stearic and palmitic fatty acid observed at its right angle did not correlate with other days' lipid sample. 
Biplot (PC1 and PC2: $96.88 \%)$

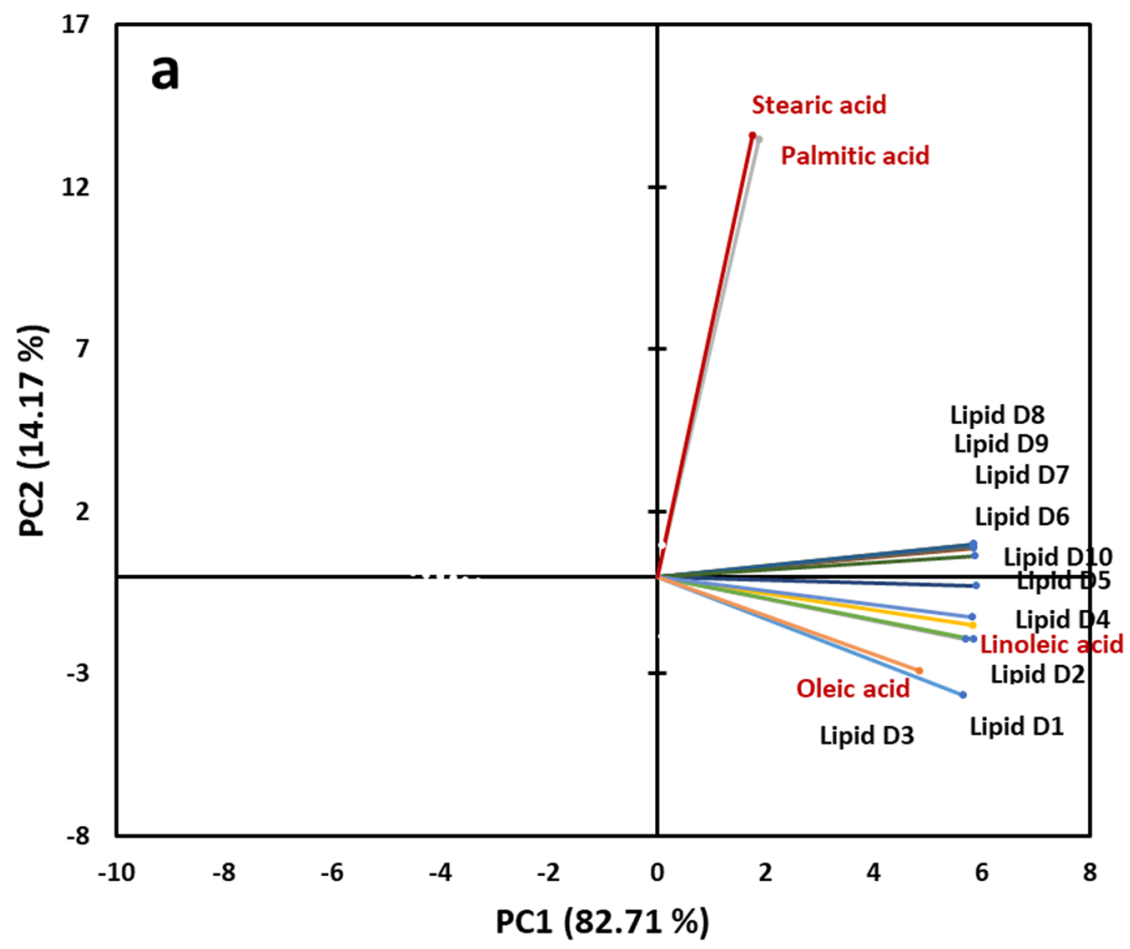

Biplot (PC1 and PC2: $94.95 \%)$

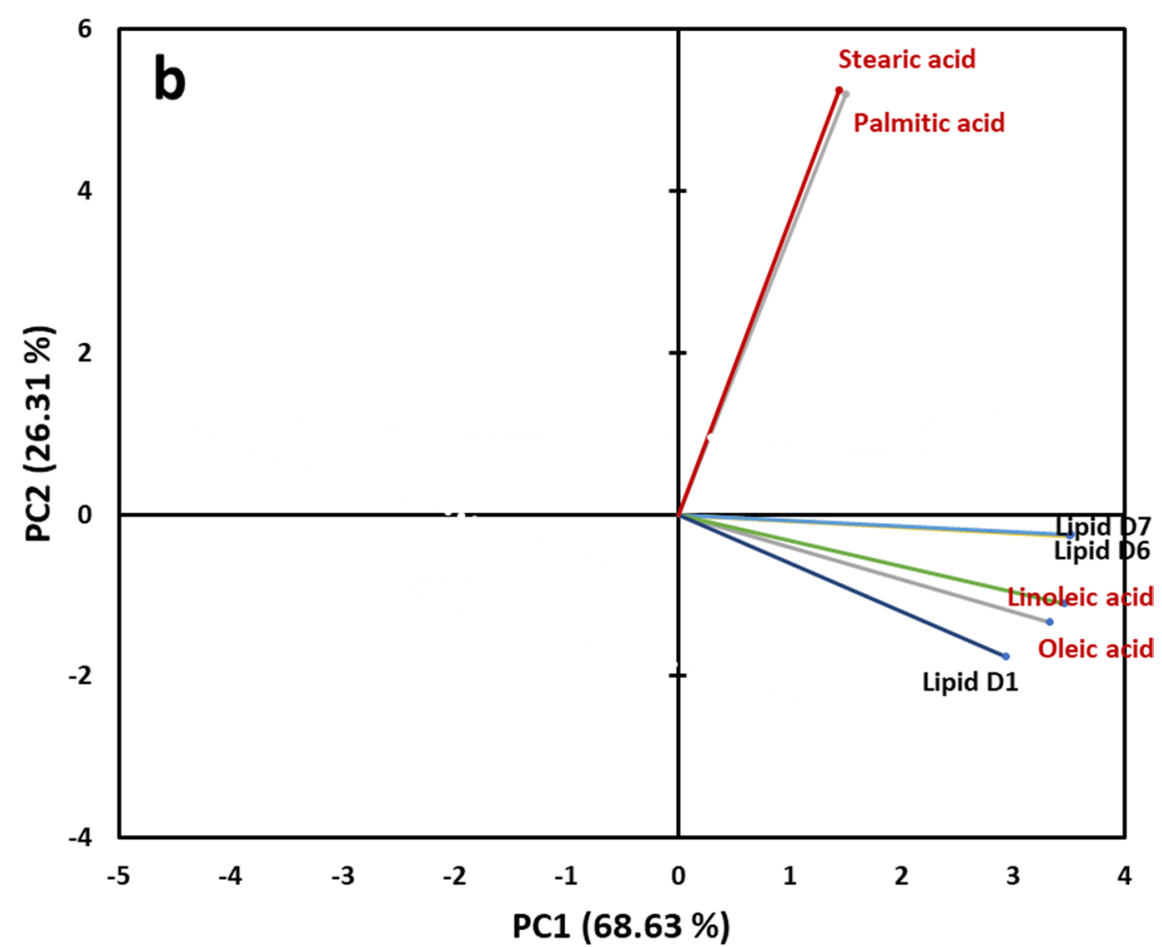

Fig. 7 PCA two-dimensional score plots of A. caespitosuS ASEF14 lipid samples and of the selected fatty acid standards, performed between 3050 and $2800 \mathrm{~cm}^{-1}$. a Lipid samples from day 1 to day $10 \mathbf{b}$. Lipid samples from day 1 and day 6 \& 7. PC1 and PC2 are reported. PCA was performed on the pre-processed FTIR data (PC: principal component) 


\section{Biplot ( PC1 and PC2: $94.30 \%$ )}

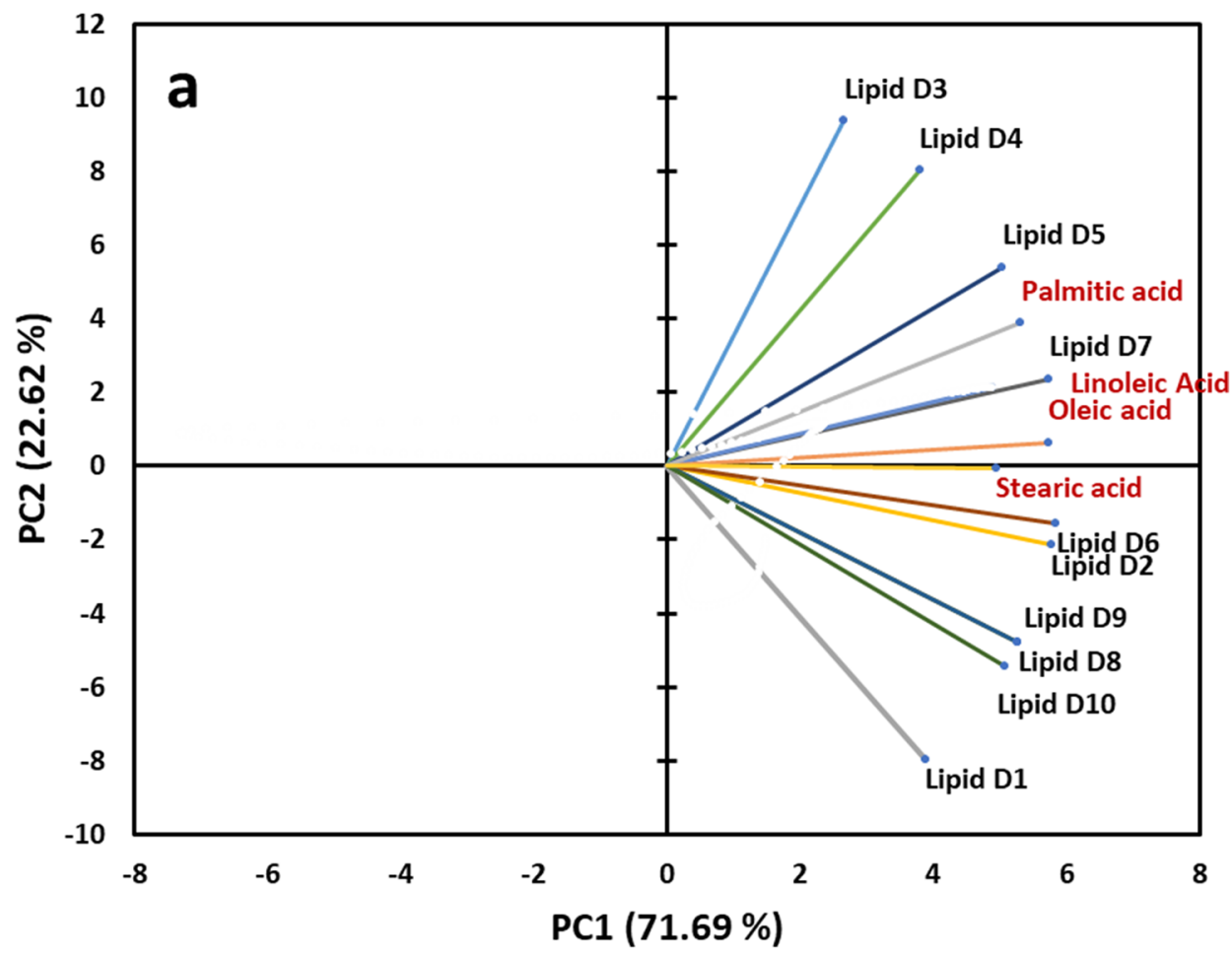

Biplot (PC1 and PC2: $90.78 \%)$

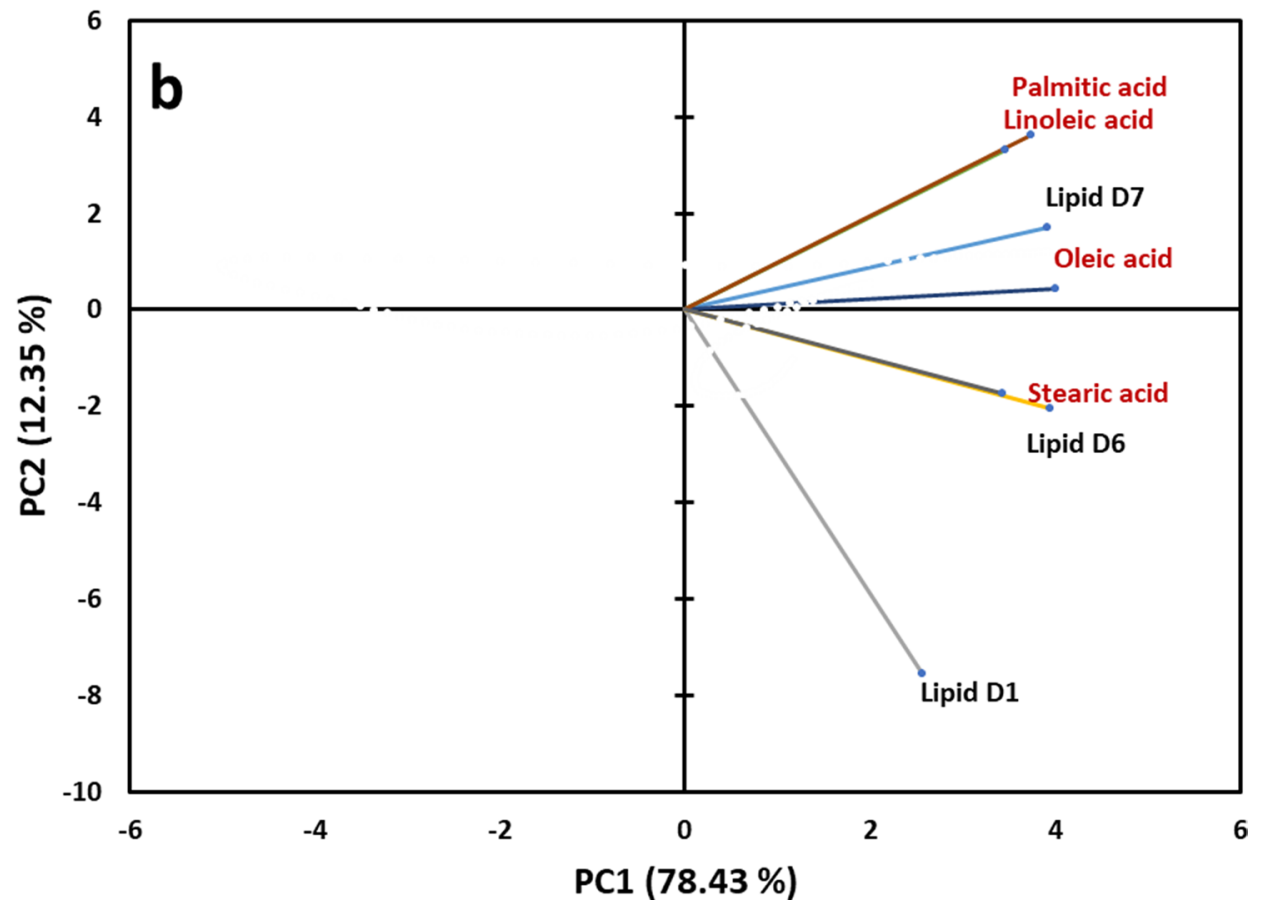

Fig. 8 PCA two-dimensional score plots of A. caespitosuS ASEF14 lipid samples and of the selected fatty acid standards, performed between 1500 and $1350 \mathrm{~cm}^{-1}$. a Lipid samples from day 1 to day $10 \mathbf{b}$. Lipid samples from day 1 and day 6 \& 7. PC1 and PC2 are reported. PCA was performed on the pre-processed FTIR data (PC: principal component) 
Further, to observe a clear time-dependent lipid profile behavior in Aspergillus, the samples were taken only at days 1, 6 and 7. Interestingly, as shown in Fig. 7b, the lipid samples of fungus at day 1 were well separated from the samples at day 6 and 7 (right angled), indicating that during the growth, the lipid spectral features changed more significantly. The relationship with standard fatty acid was the same, as mentioned earlier.

We then analyzed the absorption between 1500 and $1350 \mathrm{~cm}^{-1}$ (Fig. 8), where other vibrational modes due to lipid $\mathrm{CH}_{2}$ and $\mathrm{CH}_{3}$ occurred. The PCA of the assessed variables showed that the first and second components explain $94.30 \%$ of the total variance among the different incubation days. Of which, PC1 contributes $71.69 \%$, while PC2 adds another 22.62\% (Fig. 8a). This PCA score plots were distinct from the previous wave ranges. Day 1 sample was significantly different from the other day samples. The lipid samples at days 6 and 2 were closely related with fatty acid standard stearic acid. Day 7 sample overlapped with linoleic acid and was slightly related to palmitic and oleic fatty acids. The high-level lipid accumulation of these fatty acids was observed on these days. Day 8, 9, and 10 samples were clustered together, indicating less variation in the lipid profile $[4,69]$.

Further PCA was carried out only for the lipid samples of days 1, 6, and 7. Interestingly, the analysis between 1500 and $1350 \mathrm{~cm}^{-1}$ highlighted close connectivity of stearic acid with day 6 lipid sample (Fig. 8b). Day 7 samples were narrow angled with all other fatty acids except for stearic acid. In all cases, the results confirmed that the content of all analyzed fatty acids increased during cell growth and that the increase was again higher in mid incubation days.

\section{Fatty acid profiling of $A$. caespitosus ASEF 14 grown on SM and SWW by GC-FID}

The utilization of low-cost substrates, in addition to direct in-situ one-step conversion of lipid-containing microbial cell mass to FAMEs, is another possible option to improve the process economics of microbial biodiesel synthesis. In the present study, renewable starch-rich SWW streams were used to produce a cost-effective fuel feedstock and platform chemicals by fermentation. In oleaginous fungi, the chain length and degree of unsaturation of fatty acids depend on the growth substratum used. The diverse metabolic processes in the microorganism help to uptake the different growth substrates (as carbon sources) from the environment that can lead to diverse fatty acid composition [71]. In the present study, the differences in both the composition and concentration of fatty acids were observed in the FAME profile when the fungal strain was grown on a simple medium (SM) and a complex substrate (SWW).
When grown on SM, the fungus produced various ratios of saturated (SFA), monounsaturated (MUFA), and polyunsaturated fatty acids (PUFA) at different incubation days. Methyl palmitate (C16:0), methyl stearate (C18:0), and methyl arachidate (C20:0) were the main saturated fatty acids. The monounsaturated components were dominated by methyl elaidate $(\mathrm{C} 16: 1)$ and palmitoleate (C17:1) (Fig. 9a). The most common PUFAs were methyl linoleate and methyl linolenate. The fungi produced a significant amount of essential fatty acids such as gamma and alpha linolenate methyl esters $(36.18 \%$ and $28.20 \%$, respectively) on day 2 of incubation, followed by methyl oleate (11.67\%). The linolenic acid level of microbial oil should not exceed $12 \%$, if it is used as a biodiesel feedstock [13]. As a result, the lipid produced on this day is not acceptable as a biodiesel feedstock, but it can be used for nutritional purposes. The C16 and C18 methyl ester series were observed on days 4 to 8 of incubation. On day 6 (17.29\%) and 10 (14.87\%), the methyl oleate level was high, whereas the methyl linoleate (C18:2) concentration was high only on day $6(19.12 \%)$. On days 4 , 6 , and 8, myristic and palmitic acids were present at significant levels; however, stearic acid (C18:0) was detected only on day 6 at $32 \%$ level (Fig. 9a). With the exception on day 4 , the elaidic acid content (C18:3) was insignificant on all days, whereas PUFAs with four or more double bonds were not observed. These results suggested that a varying composition of fatty acids was produced at different incubation times by the fungal strain ASEF14, depending on the growth conditions and nutrient availability.

The fungal FAMEs obtained in SWW were rich in SFA than PUFA. The lipid profile exhibited that methyl stearate was the major fatty acid, with the highest amount of $64.77 \%$ produced on day 6 followed by day $4(43.92 \%)$ and $2(42.23 \%)$. The other major fatty acid methyl ester identified was methyl oleate, which was higher on day 10 (24.85\%) followed by days 8 and 6 (Fig. 9b). The results of the FAME profile were also confirmed by FTIR and PCA analysis, where day 6 sample completely overlapped with stearic acid and showed a close correlation with oleic acid in the spectral range of $1500-1350 \mathrm{~cm}^{-1}$.

In SWW, the proportions of oleic (C18:1) and stearic (C18:0) fatty acids were two to three times higher than other fatty acids. Throughout the incubation period, there was a low amount of methyl palmitate. This fatty acid is a key precursor in the chain elongation stage for the synthesis of other fatty acids, and it was present in very meager quantities on all incubation days in the present study. Subash and Mohan [72] obtained similar results when they cultivated Aspergillus sp. on corncob waste liquid and produced a FAME profile rich in stearic acid (48-57\%) and lacking in palmitic acids. 

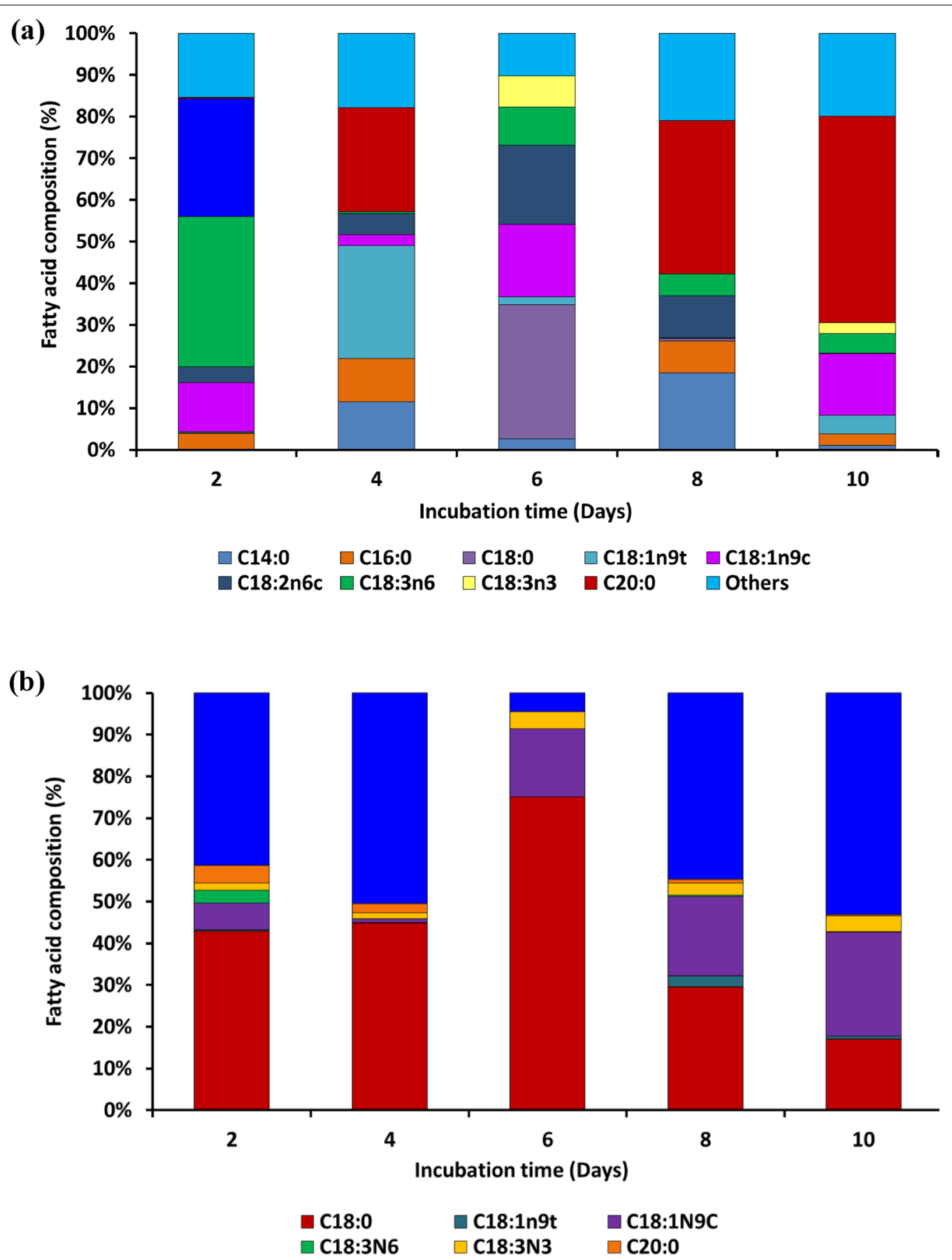

Fig. 9 a Fatty acid composition of A. caespitosus ASEF14 grown in SM. b Fatty acid composition of A. caespitosus ASEF14 grown in SWW

Muniraj et al. [17] cultured A. flavus and $M$. rouxii in PPW for $216 \mathrm{~h}$, yielding a FAME profile of myristic acid (4\% and 6\%), palmitic acid (12.4 and 10.2\%), palmitoleic acid (14.3 and 13.0\%), stearic acid (20.2 and 17.2\%), oleic acid (38.4 and 40.2\%), and linolenic acid (6.8 and 8.4\%). The oleic acid was the most predominant one.
The FAME profile of fungi from the present study was compared with the FAME profile of Aspergillus sp. cultured on several agro-industrial wastes in different studies and two commonly used vegetable oils, soybean and rapeseed (Table 3). The lipid yield and fatty acid profile of oleaginous microorganisms vary in response to 
Table 3 Comparison of FAME profile of A. caespitosus ASEF14 with different Aspergillus spp. and vegetable oils used in biodiesel production

\begin{tabular}{|c|c|c|c|c|c|c|c|c|c|c|c|}
\hline \multirow[t]{2}{*}{ S. No } & \multirow[t]{2}{*}{ Culture } & \multirow[t]{2}{*}{ Substrate/ waste type } & \multicolumn{8}{|c|}{ Fatty acid profile } & \multirow[t]{2}{*}{ References } \\
\hline & & & C14:0 & C16:0 & C16:1 & C18:0 & C18:1 & C18:2 & C18:3 & C20:0 & \\
\hline \multirow[t]{2}{*}{1} & \multirow[t]{2}{*}{ A. caespitosus ASEF14 } & SM & 2.6 & - & - & 32.22 & 17.29 & 19.12 & 9.09 & - & \multirow[t]{2}{*}{ Present study } \\
\hline & & SWW & - & 0.95 & 0.32 & 64.77 & 14.11 & 12.81 & - & 0.02 & \\
\hline 2 & A. oryzae & Potato processing wastewater & 4 & 11.6 & 15.6 & 19.3 & 30.3 & 6.5 & 5.5 & 2 & [13] \\
\hline 3 & A. niger & Sugarcane distillery wastewater & - & 24.94 & - & 5.25 & 17.23 & 42.66 & 9.92 & - & [73] \\
\hline 4 & A. terreus IBB M1 & Copra cake & 14 & 16.27 & 0.18 & 7.72 & 16.57 & 19.97 & 1.11 & 0.72 & {$[88]$} \\
\hline \multirow[t]{2}{*}{5} & \multirow[t]{2}{*}{ A. candidus IBB G4 } & Sugarcane bagasse & - & 0.4 & - & 0.5 & 14.4 & 36.8 & - & - & \multirow[t]{2}{*}{ [6] } \\
\hline & & Banana peel & - & 21.6 & - & 22.6 & 25 & 19 & - & - & \\
\hline 6 & A. candidus & Whey waste & - & 21.50 & - & 8.7 & 31.50 & 38.3 & - & - & \\
\hline 7 & A. niger 364 & Waste cooking olive oil & - & 8.9 & - & 2.7 & 80.8 & 6.9 & - & 0.7 & [89] \\
\hline 8 & A. niger LFMB1 & & - & 8.5 & & 2.4 & 69 & 8 & - & 12.1 & \\
\hline \multicolumn{12}{|c|}{ Commercial feedstock } \\
\hline 9 & Soybean oil & & - & $10-12$ & - & $3-5$ & $18-26$ & $49-57$ & $6-9$ & - & [79] \\
\hline 10 & Rapeseed oil & & - & $2-6$ & - & $4-6$ & $52-65$ & $18-25$ & $10-11$ & - & [90] \\
\hline
\end{tabular}

environmental conditions such as carbon supply, $\mathrm{pH}$, and temperature, as well as the nature of the microbe, which is species and strain specific $[2,72]$. This is supported by one of our prior investigations in which the FAME profile of the oleaginous yeast C. tropicalis ASY2 cultured on SWW [19] was completely different from that of $A$. caespitosus ASEF14 used in the current investigation by its content, quantity, and fermentation days. For example, methyl oleate was major fatty acid found in yeast, but in fungi, methyl stearate was the dominant fatty acid. Table 3 shows the differences in the FAME profiles of different Aspergillus species when grown on different agro-industrial wastes. A. niger 364 and LFMB1 strains cultivated on waste cooking oil had high methyl oleate levels of 88.8 and 69\%, respectively. Kakkad et al. [6] found that growing $A$. candidus in two different agro wastes, namely, sugarcane bagasse and banana peel, yielded $36.85 \%$ and $19 \%$ methyl linoleate, respectively. Methyl palmitate $(24.95 \%)$ and methyl linolenate (42.66\%) were abundant in $A$. niger grown on sugarcane effluent [73]. Generally, fungal FAME profiles are dominated by $\mathrm{C} 16$ and $\mathrm{C} 18$ carbon series, which are important fatty acids for biodiesel generation. This composition is quite similar to the often used biodiesel feedstock, i.e., vegetable oils.

Thus, the FAME yields obtained from ASEF14 on untreated, cheap, and renewable substrates such as SWW demonstrated the potential of the fungus in onestep saccharification-oil accumulation, allowing the direct transformation of oil-rich biomass into biodiesel. Owing to its rich saturated (C18:0; C20:0) and monounsaturated FAMEs (C18:1), as well as the absence of methyl esters with P4 double bonds, the produced fungal oil is expected to have favorable fuel qualities, such as high cetane number and enhanced oxidative stability. All these characteristics imply that the oleaginous fungi $A$. caespitosus ASEF14 is a promising candidate for microbial biodiesel production.

\section{Evaluation of fuel properties of $A$. caespitosus ASEF14 grown on SM and SWW}

Direct assessment of biodiesel fuel qualities is difficult, expensive, and time-consuming, requiring a large amount of fuel sample. As a result, mathematical equations and prediction models have been developed to predict biodiesel properties from FAME composition [74]. These equations were previously reported for $A$. terreus IBB M1 [75], A. candidus IBB G4 [6], and Yarrowia lipolytica [76]. For the commercial sale of fungus-derived fuels, it must meet the criteria set by international standards ASTM 6751-3 (USA), EN 14214 (Europe), and the Bureau of Indian Standard (IS 15607-05) [77]. On day 6, FAMEs derived from $A$. caespitosus ASEF14 grown on SM and SWW exhibited desirable FAME profiles; it was expected to have good fuel properties signifying their potential feasibility for biodiesel and are presented in Table 4. When grown on SM, the saturated, monounsaturated, and polyunsaturated FAMEs were 53.9, 16.23, and $4.82 \%$, respectively. Similarly, the fungal FAMEs of SWW were rich in saturated methyl esters (43.82\%), MUFAs (9.62\%), and PUFAs (10.87\%) and composed primarily of methyl stearate $(\mathrm{C} 18: 0,>40 \%)$ and palmitate $(\mathrm{C} 16: 0$, $20 \%)$ as major saturated FAMEs. The density of fungal biodiesel from SM and SWW was 0.65 and $0.56 \mathrm{~g} \mathrm{~cm}^{-3}$, 
Table 4 Fuel properties of FAME produced from A. caespitosus ASEF14 grown on SM and SWW

\begin{tabular}{|c|c|c|c|c|c|}
\hline \multirow[t]{2}{*}{ Fuel quality parameters } & \multirow[t]{2}{*}{ Fungal oil from SM } & \multirow{2}{*}{$\begin{array}{l}\text { Fungal oil from } \\
\text { SWW }\end{array}$} & \multicolumn{3}{|c|}{ Approved limits of biodiesel standard } \\
\hline & & & $\begin{array}{l}\text { US } \\
\text { ASTM D6751 }\end{array}$ & $\begin{array}{l}\text { Europe } \\
\text { EN } 14214\end{array}$ & $\begin{array}{l}\text { India } \\
\text { IS } 15607\end{array}$ \\
\hline Saturated fatty acid $(\%)^{* *}$ & 53.46 & 43.82 & - & - & - \\
\hline Monounsaturated fatty acid $(\%)^{* *}$ & 16.23 & 9.62 & - & - & - \\
\hline Polyunsaturated fatty acid (\%)** & 4.82 & 10.87 & - & - & - \\
\hline Degree of unsaturation** & 25.87 & 31.36 & - & - & - \\
\hline Density $\left(\mathrm{g} \mathrm{cm}^{-3}\right)^{*}$ & 0.65 & 0.56 & $0.86-0.90$ & $0.86-0.90$ & $0.86-0.90$ \\
\hline Kinematic viscosity $\left(\mathrm{mm}^{2} \mathrm{~s}^{-1}\right)^{*}$ & 3.32 & 2.62 & $1.9-6.0$ & $3.5-5$ & $2.5-6.0$ \\
\hline lodine value $\left(\mathrm{mg} \mathrm{I}_{2} 100 \mathrm{~g}^{-1}\right) *$ & 27.85 & 30.52 & - & $120 \max$ & - \\
\hline Saponification value $\left(\mathrm{mg} \mathrm{g}^{-1}\right)^{*}$ & 142.10 & 127.25 & $0.50 \max$ & $0.50 \mathrm{~min}$ & 0.5 \\
\hline Cloud point $\left({ }^{\circ} \mathrm{C}\right)^{*}$ & -3.59 & -4.66 & -15 to -5 & - & - \\
\hline Pour point $\left({ }^{\circ} \mathrm{C}\right)^{*}$ & -10.73 & -11.90 & -20 to -6 & - & - \\
\hline Higher Heating Value $\left(\mathrm{MJ} \mathrm{kg}^{-1}\right)^{*}$ & 29.80 & 25.56 & NS & NS & NS \\
\hline Oxidation stability $(\mathrm{h}) *$ & 27.06 & 13.44 & $3 \mathrm{~h} \mathrm{~min}$ & $6 \mathrm{~h} \min$ & - \\
\hline Cetane number* & 78.44 & 82.32 & $47 \mathrm{~min}$ & $51 \mathrm{~min}$ & $51 \mathrm{~min}$ \\
\hline Concentration of $y$-linolenic acid (C18:3) (\%)** & $<5$ & $<9$ & NS & $12 \max$ & NS \\
\hline FAME having $\geq 4$ double bonds ** & ND & ND & NS & $1 \max$ & NS \\
\hline
\end{tabular}

* predicted values as mentioned in Methods

** experimentally determined values by GC-FID according to standard AOAC methods

ND Not detected, NS not specified

which is slightly lower than standard limits (0.86$0.90 \mathrm{~g} \mathrm{~cm}^{-3}$ ). The KV, IV, CP, and PP were in accordance with all biodiesel standards indicating the potential use of fungal oil as biodiesel. IV is a crude measure of the degree of unsaturation of biodiesel and is often used in connection with its oxidative stability. SV indicates the number of TAGs present in total lipid, and HHV depends on both IV and SV. Therefore, we calculated both SV and IV empirically from the fatty ester composition of in situ transesterified lipids and were found to be in good agreement with each other. The IV of fungal oil was low in SM (27.85 $\mathrm{g} \mathrm{I}_{2} / 100 \mathrm{~g}$ of oil) and SWW (30.52 $\mathrm{g} \mathrm{I}_{2} / 100 \mathrm{~g}$ of oil), which are below the EN specification (120 max), indicating good oxidative stability of the oil [78]. The SV values were 142.10 and 127.25 , whereas $H H V$ values were 29.8 and $25.56 \mathrm{MJ} \mathrm{kg}^{-1}$ for SM and SWW, respectively. OS is an important yardstick to determine the self-life of the engine. In this study, the OS value of fungal biodiesel derived from SM and SWW were 27.06 and $13.44 \mathrm{~h}$, respectively. This high OS content might be due to more number of double bonds or unsaturated bonds in the oil.

Cetane number $(\mathrm{CN})$ is a property of fuel that decides its ignition quality. The methyl esters of stearic acid (C18:0), which are of relevance to biodiesel, have been found to possess the highest $\mathrm{CN}(>80)$ [79]. We found that the methyl esters of long-chain saturated fatty acids, namely stearic acid (C18:0) and palmitic acid (C16:0), were present in a higher percentage in the FAME profile of $A$. caespitosus ASEF14 grown on SWW. The CN values for fungal biodiesel of SM and SWW were 78.44 and 82.32, respectively, which are substantially higher than conventional petro-diesel fuels that fall within the range of 47 to 51 . Previously, the yeast Candida tropicalis ASY2 biodiesel had a CN value of 61 [14]. The CN value of 70 was reported earlier for biodiesel from microalga Spirulina platensis [80]. Higher $\mathrm{CN}$ in the fungusderived biodiesel can be attributed to an increase in saturated FAME content and its chain length. Higher $\mathrm{CN}$ results in higher combustion efficiency, improved engine performance, and cleaner emissions so that it can be recommended for use in the high-speed engine (above $800 \mathrm{rpm}$ ) [80]. Conversely, a fuel with low $\mathrm{CN}$ will cause difficulty in engine starting, generating higher noise and exhaust smoke [80]. Another crucial fuel quality that has been included in EN 14214 specification is the concentration of linolenic acid (C18:3), produced below the specified limit of 12 max, and fatty esters with $\geq 4$ double bonds that were not detected in both SM and SWW of fungal FAMEs (Table 4). These values are in the acceptable range of international biodiesel standard norms, suggesting the suitability of SWW grown ASEF14-derived biodiesel. 
Table 5 Physicochemical characteristics of treated SWW

\begin{tabular}{|c|c|c|c|}
\hline \multirow[t]{2}{*}{ Parameters } & \multicolumn{2}{|l|}{ Values $\left(\mathrm{g} \mathrm{L}^{-1}\right)$} & \multirow[t]{2}{*}{$\%$ reduction } \\
\hline & Raw SWW & Treated SWW & \\
\hline $\mathrm{pH}$ & $4.30( \pm 0.0)$ & $9.13( \pm 0.0)$ & - \\
\hline Electrical conductivity $\left(\mathrm{dS} \mathrm{m}^{-1}\right)$ & $6.21( \pm 0.0)$ & $4.11( \pm 0.0)$ & - \\
\hline Salinity (ppt) & $4.53( \pm 0.0)$ & $3.15( \pm 0.0)$ & 30.6 \\
\hline Total dissolved solids (TDS) & $4.07( \pm 0.0)$ & $2.64( \pm 0.1)$ & 35.2 \\
\hline Total suspended solids (TSS) & $6.67( \pm 0.8)$ & $3.14( \pm 0.5)$ & 53.0 \\
\hline Total solids (TS) & $6.90( \pm 0.1)$ & $2.86( \pm 0.6)$ & 58.6 \\
\hline Total phosphate (TP) & $1.06( \pm 0.0)$ & $0.06( \pm 0.0)$ & 94.5 \\
\hline Total nitrogen (TN) & $0.44( \pm 0.0)$ & $0.05( \pm 0.0)$ & 89.3 \\
\hline Dissolved oxygen (DO) & $7.84( \pm 0.6)$ & $0.68( \pm 0.0)$ & 91.3 \\
\hline Biochemical oxygen demand (BOD) & $2.56( \pm 0.5)$ & $0.67( \pm 0.0)$ & 74.0 \\
\hline Chemical oxygen demand (COD) & $76.00( \pm 6.9)$ & $40.27( \pm 0.5)$ & 47.0 \\
\hline Starch & $6.10( \pm 0.8)$ & - & - \\
\hline Starch* & $30.00( \pm 0.0)$ & $11.12( \pm 1.7)$ & 62.9 \\
\hline Cyanide $\left(\mathrm{mg} \mathrm{L}^{-1}\right)$ & $5.2( \pm 1.0)$ & $2.4( \pm 0.02)$ & 53.84 \\
\hline
\end{tabular}

Values represent mean ( \pm standard error) $(n=3)$

* The initial starch concentration in the SWW was adjusted to $30 \mathrm{~g} \mathrm{~L}^{-1}$

\section{Integrated decontamination of SWW and lipid production by $A$. caespitosus ASEF14}

The fungal strain ASEF14 was grown on SWW for ten days. After fermentation, the mycelium was harvested, and lipids were extracted using chloroform and methanol. The spent wastewater was filtered and used to analyze the physicochemical parameters and then compared with raw SWW (Table 5). Physicochemical analysis of raw and treated SWW showed that the fungal strain increased the $\mathrm{pH}$ from acidity $(\mathrm{pH}$ 6) to alkalinity $(\mathrm{pH}$ 9.13) due to the secretion of amines and related compounds [81]. The electrical conductivity was very high

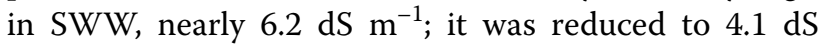
$\mathrm{m}^{-1}$ after the treatment. The organic substances such as TS, TDS, and TSS from tapioca tuber extraction in the wastewater were reduced to $58.6 \%, 53 \%$, and $35.2 \%$, respectively. The nutrients present in the wastewater, such as total nitrogen $\left(0.44 \mathrm{~g} \mathrm{~L}^{-1}\right)$ and phosphate levels $\left(1.06 \mathrm{~g} \mathrm{~L}^{-1}\right)$ (Table 5), were removed to a level of $89.3 \%$ and $94.5 \%$, respectively. This was comparable with our earlier reports on decontamination of SWW by oleaginous yeast $C$. tropicalis ASY2 that registered removal of nitrate $\left(\mathrm{NO}_{3}\right)$, ammonia $\left(\mathrm{NH}_{4}\right)$, and phosphate $\left(\mathrm{PO}_{4}\right)$ ions in the level of $100 \%, 98 \%$, and $85 \%$, respectively [14]. In our study, the initial starch content of $6.1 \mathrm{~g} \mathrm{~L}^{-1}$ was in accordance with previous reports [82, 83], and it was adjusted to $30 \mathrm{~g} \mathrm{~L}^{-1}$ before the fermentation process started. At the end of fermentation, the residual sugar level in the SWW was $11.12 \mathrm{~g} \mathrm{~L}^{-1}$ indicated the starch utilization efficiency of fungi. The dissolved oxygen $(91.3 \%)$, BOD (74\%), and COD (47\%) were reduced to a considerable level. The change in the COD and BOD could be attributed to the effective use of nutrients available in wastewater by the fungi. The nutrient removal efficiency of $A$. caespitosus ASEF14 was compared with the following studies. Xue et al. [12] used monosodium glutamate wastewater as a fermentable medium for lipid production using Rhodotorula glutinis. Because the wastewater contained nitrogen, favoring biomass growth but not lipid accumulation, glucose was added at various levels, namely initial, fed-batch, and feedback addition. Of these, the feedback addition yielded $20 \%$ of lipid content and 45\% COD removal. Xue et al. [58] cultivated R. glutinis by non-aseptic fermentation using corn starch wastewater for lipid production and achieved 35\% of lipid content and $80 \%$ of COD reduction. Muniraj et al. [17] treated PPW, which efficiently removed soluble COD, total soluble nitrogen, and total soluble phosphorus up to $60 \%$ and $90 \%, 100 \%$ and $98 \%$, and $92 \%$ and $81 \%$, and produced lipid yield of 2.8 and $3.6 \mathrm{~g} \mathrm{~L}^{-1}$ by $A$. flavus I16-3 and $M$. rouxii, respectively. Nzayisenga et al. [84] treated municipal wastewater using four algal strains (Chlorella vulgaris, Desmodesmus sp., Ettlia pseudoalveolaris, and Scenedesmus obliquus) along with lipid production. All strains removed more than $75 \%$ of the total nitrogen and phosphorus content of the treated wastewater after 8 days.

Similarly, oleaginous fungus $A$. caespitosus ASEF14 effectively used various nutrients in the wastewater as growth components and produced high lipid content (37.27\%). In addition, the fungal strain reduced cyanide toxicity levels by up to $50 \%$ which was less than from our 
previous report [14] indicates the tolerable level of fungi to the toxicant cyanide.

\section{Conclusion}

Our study clearly indicates that, there are marked differences between oleaginous yeast and fungi in terms of substrate utilization efficiency, sugar requirement, lipid accumulation pathways, FAME composition, and respective fuel properties when cultivated on the same substrate. Both organisms have their own advantages and disadvantages. A. caespitosus ASEF14 exhibited high lipid content of $54 \%$ in SM and $37.27 \%$ in SWW with a fatty acid profile similar to that of vegetable oils (soybean and rapeseed), which are currently employed in biodiesel production. Moreover, SWW-derived biodiesel properties (CN: 82.32, IV: $30.53 \mathrm{~g} \mathrm{~g}^{-1}$, KV: 2.62 $\mathrm{mm}^{2} \mathrm{~s}^{-1}, \mathrm{CP}: 4.66^{\circ} \mathrm{C}$, and PP: $11.90^{\circ} \mathrm{C}$ ) were in accordance with the existing biodiesel standards. Therefore, the use of oleaginous fungus A. caespitosus ASEF14 isolated from SWW as myco-diesel holds immense potential for current diesel substitution. In addition, it is an efficient method to decontaminate SWW by reducing COD, BOD, various nutrients, and toxicants at a considerable level. This kind of myco-diesel or biodiesel has the potential to be used as a substitute for fossil fuels, especially when several countries are attempting to find alternative sources, owing to its low cost and eco-friendly nature of production.

\begin{abstract}
Abbreviations
SWW: Sago processing wastewater; SM: Synthetic medium; COD: Chemical oxygen demand; BOD: Biological/Biochemical oxygen demand; ASTM: American Society for Testing and Materials; EN: European standards; DCW: Dry cell weight; ANOVA: Analysis of variance; KV: Kinematic viscosity; SV: Saponification value; IV: Iodine value; HHV: Higher heating value; CV: Cetane number; LCSF: Long-chain saturated factor; CFPP: Cold filter plugging point; CP: Cloud point; PP: Pour point; DU: Degree of unsaturation.
\end{abstract}

\section{Acknowledgements}

We acknowledge the Metabolomic and Proteomic Analytical Facility (MPAF) at Tamil Nadu Agricultural University, Coimbatore, India for sharing their equipment for various analyses carried out in the present study.

\section{Authors' contributions}

Conceptualized the idea and received research grants from DBT: SU. Experiments designed: SU, NS, KT, AS. Experiments conducted: NS, KT, AS, SB. Data analyzed and results discussed: NS and SU. Manuscript written: NS \& KT. Edited, reviewed and approved: SU. All the authors helped in reviewing the whole manuscript. All authors read and approved the final manuscript.

\section{Funding}

We thank the DBT-Biodiesel project on "Biodiesel production: Sago processing industrial wastewater as feedstock's for the microbial production of oil and derived co-products" granted to SU (File No.BT/PR8280/PBD/26/382/2013 dated. 20.03.2015)" for financial support. We also thank the Ministry of Human Resource Development, Government of India through MHRD-FAST-CoE (F.No.5-6/2013-TSVII) sanctioned to SU.
Availability of data and materials

All data generated or analyzed during this study are included in this published article.

\section{Declarations}

Ethics approval and consent to participate

Not applicable.

\section{Consent for publication}

All authors have participated in a research study and MS preparation.

\section{Competing interests}

The authors hereby declare that they have no conflict of interest.

\section{Author details}

${ }^{1}$ Biocatalysts Laboratory, Deptartment of Agricultural Microbiology, Tamil Nadu Agricultural University, Coimbatore 641 003, India. ${ }^{2}$ Department of Renewable Energy Engineering, Agricultural Engineering College \& Research Institute, Tamil Nadu Agricultural University, Coimbatore 641003 , India.

Received: 13 March 2021 Accepted: 25 August 2021

Published online: 09 September 2021

\section{References}

1. Hill J, Nelson E, Tilman D, Polasky S, Tiffany D. Environmental, economic, and energetic costs and benefits of biodiesel and ethanol biofuels. Proc Natl Acad Sci. 2006;103:11206-10.

2. Subramaniam R, Dufreche S, Zappi M, Bajpai R. Microbial lipids from renewable resources: production and characterization. J Ind Microbiol Biotechnol. 2010;37:1271-87.

3. Meeuwse P, Sanders JP, Tramper J, Rinzema A. Lipids from yeasts and fungi: tomorrow's source of biodiesel? Biofuels, Bioprod Biorefin. 2013;7:512-24.

4. Ami D, Posteri R, Mereghetti P, Porro D, Doglia SM, Branduardi P. Fourier transform infrared spectroscopy as a method to study lipid accumulation in oleaginous yeasts. Biotechnol Biofuels. 2014;7:12.

5. Socha AM, Sello JK. Efficient conversion of triacylglycerols and fatty acids to biodiesel in a microwave reactor using metal triflate catalysts. Org Biomol Chem. 2010;8:4753-6.

6. Kakkad H, Khot M, Zinjarde S, RaviKumar A. Biodiesel production by direct in situ transesterification of an oleaginous tropical mangrove fungus grown on untreated agro-residues and evaluation of its fuel properties. BioEnergy Res. 2015;8:1788-99.

7. Uthandi S, Kaliyaperumal A, Srinivasan N, Thangavelu K, Muniraj IK, Zhan X, Gathergood N, Gupta VK. Microbial biodiesel production from lignocellulosic biomass: new insights and future challenges. Crit Rev Environ Sci Technol. 2021. https://doi.org/10.1080/10643389.2021.1877045.

8. Zheng Y, Yu X, Zeng J, Chen S. Feasibility of filamentous fungi for biofuel production using hydrolysate from dilute sulfuric acid pretreatment of wheat straw. Biotechnol Biofuels. 2012;5:1-10.

9. André A, Diamantopoulou P, Philippoussis A, Sarris D, Komaitis M, Papanikolaou S. Biotechnological conversions of bio-diesel derived waste glycerol into added-value compounds by higher fungi: production of biomass, single cell oil and oxalic acid. Ind Crops Prod. 2010;31:407-16.

10. Gnanaprakasam A, Sivakumar V, Surendhar A, Thirumarimurugan M, Kannadasan T. Recent strategy of biodiesel production from waste cooking oil and process influencing parameters: a review. J Energy. 2013;2013:1-11.

11. Sadaf S, Iqbal J, Ullah I, Bhatti HN, Nouren S, Nisar J, lqbal M. Biodiesel production from waste cooking oil: an efficient technique to convert waste into biodiesel. Sustain Cities Soc. 2018;41:220-6. 
12. Xue F, Miao J, Zhang X, Luo H, Tan T. Studies on lipid production by Rhodotorula glutinis fermentation using monosodium glutamate wastewater as culture medium. Biores Technol. 2008;99:5923-7.

13. Muniraj IK, Xiao L, Hu Z, Zhan X, Shi J. Microbial lipid production from potato processing wastewater using oleaginous filamentous fungi Aspergillus oryzae. Water Res. 2013;47:3477-83.

14. Thangavelu K, Sundararaju P, Srinivasan N, Muniraj I, Uthandi S. Simultaneous lipid production for biodiesel feedstock and decontamination of sago processing wastewater using Candida tropicalis ASY2. Biotechnol Biofuels. 2020;13:1-14

15. Huang C, Chen X-f, Xiong L, Ma L-I, Chen Y. Single cell oil production from low-cost substrates: the possibility and potential of its industrialization. Biotechnol Adv. 2013:31:129-39.

16. Yousuf A. Biodiesel from lignocellulosic biomass-prospects and challenges. Waste Manage. 2012;32:2061-7.

17. Muniraj IK, Xiao L, Liu H, Zhan X. Utilisation of potato processing wastewater for microbial lipids and $\gamma$-linolenic acid production by oleaginous fungi. J Sci Food Agric. 2015;95:3084-90.

18. Ashika S, Kiruthika T, Ashokkumar K, Suraj H, Uthandi S. Oleaginous yeast from sago waste water: screening and characterization of Candida trophicalis for biolipid production. Madras Agric J. 2017;104:288.

19. Thangavelu K, Sundararaju P, Srinivasan N, Uthandi S. Characterization of biomass produced by Candida tropicalis ASY2 grown using sago processing wastewater for bioenergy applications and its fuel properties. Biomass Convers Biorefinery. 2021. https://doi.org/10.1007/ s13399-020-01129-7.

20. APHA. Standard methods for the examination of water and wastewater. Federation, Water Environmental APH Association, American Public Health Association, Washington, DC, USA 2005.

21. Kirk PL. Kjeldahl method for total nitrogen. Anal Chem. 1950;22:354-8.

22. Dubois M, Gilles K, Hamilton J, Roberts P, Smith F. Phenol sulphuric acid method for carbohydrate determination. Anal Chem. 1956;28:350-9.

23. Fisher F, Brown J. Colorimetric determination of cyanide in stack gas and waste water. Anal Chem. 1952;24:1440-4.

24. Bosshard PP. Incubation of fungal cultures: how long is long enough? Mycoses. 2011:54:539-45.

25. Sharma D, Shukla A. Starch hydrolysis and alpha-amylase activity of Aspergillus and Chaetomium. Asian J Biochem. 2008;3:284-9.

26. Zak JC, Wildman HG. Fungi in stressful environments. In: Biodiversity of fungi: Inventory monitoring methods; 2004, p. 303-15.

27. Rath C, Subramanyam V. Isolation of thermophilic bacteria from hot springs of Orissa, India. Geobios. 1998;25:113-9.

28. Kimura K, Yamaoka M, Kamisaka Y. Rapid estimation of lipids in oleaginous fungi and yeasts using Nile red fluorescence. J Microbiol Methods. 2004;56:331-8.

29. Koutb M, Morsy FM. A potent lipid producing isolate of Epicoccum purpurascens AUMC5615 and its promising use for biodiesel production. Biomass Bioenergy. 2011;35:3182-7.

30. Suutari M, Priha P, Laakso S. Temperature shifts in regulation of lipids accumulated by Lipomyces starkeyi. J Am Oil Chem Soc. 1993;70:891-4.

31. Kumar I, Ramalakshmi M, Sivakumar U, Santhanakrishnan P, Zhan X. Production of microbial oils from Mortierella sp for generation of biodiesel livestock. Afr J Microbiol Res. 2011;5:4105-11.

32. Folch J, Lees M, Sloane-Stanley G. A simple method for the isolation and purification of total lipids from animal tissues. J Biol Chem. 1957;226:497-509.

33. Doyle J, Doyle J. Genomic plant DNA preparation from fresh tissue-CTAB method. Phytochem Bull. 1987;19:11-5.

34. Saitou N, Nei M. The neighbor-joining method: a new method for reconstructing phylogenetic trees. Mol Biol Evol. 1987:4:406-25.

35. Tamura K, Peterson D, Peterson N, Stecher G, Nei M, Kumar S. MEGA5: molecular evolutionary genetics analysis using maximum likelihood, evolutionary distance, and maximum parsimony methods. Mol Biol Evol. 2011:28:2731-9.

36. Bernfeld P. [17] Amylases, a and B. Methods Enzymol. 1955;1:149-58.

37. Wold S, Esbensen K, Geladi P. Principal component analysis. Chemom Intell Lab Syst. 1987;2:37-52.

38. Rencher AC. Methods of multivariate analysis. New York: Wiley; 2003.

39. Knothe $\mathrm{G}$. Dependence of biodiesel fuel properties on the structure of fatty acid alkyl esters. Fuel Process Technol. 2005;86:1059-70.
40. Ramírez-Verduzco LF, Rodríguez-Rodríguez JE, del Rayo J-J. Predicting cetane number, kinematic viscosity, density and higher heating value of biodiesel from its fatty acid methyl ester composition. Fuel. 2012;91:102-11.

41. Knothe G. Biodiesel and its properties. In: Industrial Oil Crops. Elsevier; 2016: 15-42.

42. Patel A, Arora N, Mehtani J, Pruthi V, Pruthi PA. Assessment of fuel properties on the basis of fatty acid profiles of oleaginous yeast for potential biodiesel production. Renew Sustain Energy Rev. 2017;77:604-16.

43. Sarin A, Arora R, Singh N, Sarin R, Malhotra R, Kundu K. Effect of blends of Palm-Jatropha-Pongamia biodiesels on cloud point and pour point. Energy. 2009;34:2016-21.

44. Abdulvahitoğlu A. Predicted fuel characteristics of Prunus avium seed oil as a candidate for biodiesel production. Int J Automotive Eng Technol. 2019;8:165-71.

45. Papanikolaou S, Galiotou-Panayotou M, Fakas S, Komaitis M, Aggelis G. Lipid production by oleaginous Mucorales cultivated on renewable carbon sources. Eur J Lipid Sci Technol. 2007;109:1060-70.

46. Kang S, ParkY, Lee J, Hong S, Kim S. Production of cellulases and hemicellulases by Aspergillus niger KK2 from lignocellulosic biomass. Biores Technol. 2004;91:153-6.

47. Subhash GV, Mohan SV. Lipid accumulation for biodiesel production by oleaginous fungus Aspergillus awamori: Influence of critical factors. Fuel. 2014;116:509-15.

48. Ratledge C, Wynn JP. The biochemistry and molecular biology of lipid accumulation in oleaginous microorganisms. Adv Appl Microbiol. 2002;51:1-52.

49. Sitepu I, Ignatia L, Franz A, Wong D, Faulina S, Tsui M, Kanti A, BoundyMills K. An improved high-throughput Nile red fluorescence assay for estimating intracellular lipids in a variety of yeast species. J Microbiol Methods. 2012:91:321-8.

50. Greenspan P, Mayer EP, Fowler SD. Nile red: a selective fluorescent stain for intracellular lipid droplets. J Cell Biol. 1985;100:965-73.

51. Ling X, Guo J, Liu X, Zhang X, Wang N, Lu Y, Ng I-S. Impact of carbon and nitrogen feeding strategy on high production of biomass and docosahexaenoic acid (DHA) by Schizochytrium sp. LU310. Bioresour Technol. 2015;184:139-47.

52. Vicente G, Bautista LF, Gutiérrez FJ, Rodríguez R, Martínez V, RodríguezFrómeta RA, Ruiz-Vázquez RM, Torres-Martínez S, Garre V. Direct transformation of fungal biomass from submerged cultures into biodiesel. Energy Fuels. 2010;24:3173-8.

53. White TJ, Bruns T, Lee S, Taylor JJP. Amplification and direct sequencing of fungal ribosomal RNA genes for phylogenetics. PCR Protocols. 1990;18:315-22.

54. Vorapreeda T, Thammarongtham C, Cheevadhanarak S, Laoteng K. Alternative routes of acetyl-CoA synthesis identified by comparative genomic analysis: involvement in the lipid production of oleaginous yeast and fungi. Microbiology. 2012;158:217-28.

55. Thammarongtham C, Nookaew I, Vorapreeda T, SrisukT, Land ML, Jeennor S, Laoteng K. Genome characterization of oleaginous Aspergillus oryzae BCC7051: a potential fungal-based platform for lipid production. Curr Microbiol. 2018;75:57-70.

56. Pietrocola F, Galluzzi L, Bravo-San Pedro JM, Madeo F, Kroemer G. Acetyl coenzyme A: a central metabolite and second messenger. Cell Metab. 2015;21:805-21.

57. Zhao L, Cánovas-Márquez JT, Tang X, Chen H, Chen YQ, Chen W, Garre $\checkmark$, Song $Y$, Ratledge $C$. Role of malate transporter in lipid accumulation of oleaginous fungus Mucor circinelloides. Appl Microbiol Biotechnol Biofuels. 2016;100:1297-305.

58. Xue F, Gao B, Zhu Y, Zhang X, Feng W, Tan T. Pilot-scale production of microbial lipid using starch wastewater as raw material. Biores Technol. 2010;101:6092-5.

59. Chi Z, Pyle D, Wen Z, Frear C, Chen S. A laboratory study of producing docosahexaenoic acid from biodiesel-waste glycerol by microalgal fermentation. J Process Biochem. 2007:42:1537-45.

60. Ratledge C, Cohen Z. Microbial and algal oils: do they have a future for biodiesel or as commodity oils? Lipid Technol. 2008;20:155-60.

61. Shapaval V, Møretrø T, Suso HP, Åsli AW, Schmitt J, Lillehaug D, Martens H, Böcker U, Kohler A. A high-throughput microcultivation protocol for FTIR spectroscopic characterization and identification of fungi. J Biophotonics. 2010;3:512-21. 
62. Shapaval V, Walczak B, Gognies S, Møretrø T, Suso H, Åsli AW, Belarbi A, Kohler A. FTIR spectroscopic characterization of differently cultivated food related yeasts. Analyst. 2013;138:4129-38.

63. Vongsvivut J, Heraud P, Gupta A, Thyagarajan T, Puri M, McNaughton D, Barrow CJJP. Synchrotron-FTIR microspectroscopy enables the distinction of lipid accumulation in thraustochytrid strains through analysis of individual live cells. Protist. 2015;166:106-21.

64. Natalello A, Ami D, Doglia SM. Fourier transform infrared spectroscopy of intrinsically disordered proteins: measurement procedures and data analyses. In: Uversky VN, Keith Dunker A, editors. Intrinsically disordered protein analysis. Berlin: Springer; 2012. p. 229-44.

65. Tamm LK, Tatulian SA. Infrared spectroscopy of proteins and peptides in lipid bilayers. Q Rev Biophys. 1997;30:365-429.

66. Casal HL, Mantsch HH. Polymorphic phase behaviour of phospholipid membranes studied by infrared spectroscopy. Biochimica et Biophysica Acta -Reviews on Biomembranes. 1984;779:381-401.

67. Dzurendova S, Zimmermann B, Kohler A, Tafintseva V, Slany O, Certik M, Shapaval V. Microcultivation and FTIR spectroscopy-based screening revealed a nutrient-induced co-production of high-value metabolites in oleaginous Mucoromycota fungi. PLoS ONE. 2020;15:1-15.

68. Deeba F, Pruthi V, Negi YS. Converting paper mill sludge into neutral lipids by oleaginous yeast Cryptococcus vishniaccii for biodiesel production. Biores Technol. 2016;213:96-102.

69. Signori L, Ami D, Posteri R, Giuzzi A, Mereghetti P, Porro D, Branduardi P. Assessing an effective feeding strategy to optimize crude glycerol utilization as sustainable carbon source for lipid accumulation in oleaginous yeasts. Microb Cell Fact. 2016;15:1-19.

70. Shapaval V, Brandenburg J, Blomqvist J, Tafintseva V, Passoth V, Sandgren $M$, Kohler A. Biochemical profiling, prediction of total lipid content and fatty acid profile in oleaginous yeasts by FTIR spectroscopy. Biotechnol Biofuels. 2019;12:1-12.

71. Ratledge C. Biotechnology of oils and fats. Microbial lipids. 1989:2:567-668.

72. Subhash GV, Mohan SV. Sustainable biodiesel production through bioconversion of lignocellulosic wastewater by oleaginous fungi. Biomass Convers Biorefinery. 2015;5:215-26.

73. Chuppa-Tostain G, Hoarau J, Watson M, Adelard L, Sing ASC, Caro Y, Grondin I, Bourven I, Francois J-M, Girbal-Neuhauser E. biotechnology: Production of Aspergillus niger biomass on sugarcane distillery wastewater: physiological aspects and potential for biodiesel production. Fungal Biol. 2018;5:1-12.

74. Verma P, Sharma M, Dwivedi G. Impact of alcohol on biodiesel production and properties. Renew Sustain Energy Rev. 2016;56:319-33.

75. Khot M, Kamat S, Zinjarde S, Pant A, Chopade B, RaviKumar A. Single cell oil of oleaginous fungi from the tropical mangrove wetlands as a potential feedstock for biodiesel. Microb Cell Fact. 2012;11:71.

76. Katre G, Joshi C, Khot M, Zinjarde S, RaviKumar A. Evaluation of single cell oil (SCO) from a tropical marine yeast Yarrowia lipolytica NCIM 3589 as a potential feedstock for biodiesel. AMB Express. 2012;2:36.
77. Atadashi I, Aroua MK, Aziz AA. High quality biodiesel and its diesel engine application: a review. Renew Sustain Energy Rev. 2010;14:1999-2008.

78. Jose TK, Anand K. Effects of biodiesel composition on its long term storage stability. Fuel. 2016;177:190-6.

79. Knothe G. "Designer" biodiesel: optimizing fatty ester composition to improve fuel properties. Energy Fuels. 2008;22:1358-64.

80. Mostafa SS, El-Gendy NS. Evaluation of fuel properties for microalgae Spirulina platensis bio-diesel and its blends with Egyptian petro-diesel. Arab J Chem. 2017;10:S2040-50.

81. de Lima DP, dos Santos EDA, Marques MR, Giannesi GC, Beatriz A, Yonekawa MK, Montanholi ADS. Fungal bioremediation of pollutant aromatic amines. Curr Opinion Green Sustain Chem. 2018;11:34-44.

82. Pandian P, Meenambal T. Development and performance analysis of twostage biological process adopted in sago industries for treatment of high organic effluent. Int J Res Advent Technol. 2017;5:7-11.

83. Sen B, Suttar RR. Mesophilic fermentative hydrogen production from sago starch-processing wastewater using enriched mixed cultures. Int J Hydrogen Energy. 2012;37:15588-97.

84. Nzayisenga JC, Farge X, Groll SL, Sellstedt A. Effects of light intensity on growth and lipid production in microalgae grown in wastewater. Biotechnol Biofuels. 2020;13:1-8.

85. Forfang K, Zimmermann B, Kosa G, Kohler A, Shapaval V. FTIR spectroscopy for evaluation and monitoring of lipid extraction efficiency for oleaginous fungi. PLOS ONE. 2017;12:e0170611.

86. Guillén MD, Cabo N. Relationships between the composition of edible oils and lard and the ratio of the absorbance of specific bands of their Fourier transform infrared spectra. Role of some bands of the fingerprint region. J Agric Food Chem. 1998;46:1788-93.

87. Vongsvivut J, Heraud P, Gupta A, Puri M, MCNaughton D, Barrow CJ. FTIR microspectroscopy for rapid screening and monitoring of polyunsaturated fatty acid production in commercially valuable marine yeasts and protists. Analyst. 2013;138:6016-31.

88. Khot M, Gupta R, Barve K, Zinjarde S, Govindwar S, RaviKumar A. Fungal production of single cell oil using untreated copra cake and evaluation of its fuel properties for biodiesel. J Microbiol Biotechnol. 2015;25:459-63.

89. Papanikolaou S, Aggelis G. Lipids of oleaginous yeasts. Part I: Biochemistry of single cell oil production. Eur J Lipid Sci Technol. 2011;113:1031-51.

90. Snåre M, Mäki-Arvela P, Simakova I, Myllyoja J, Murzin DYJR. Overview of catalytic methods for production of next generation biodiesel from natural oils and fats. J Phys Chem. 2009;3:1035-43.

\section{Publisher's Note}

Springer Nature remains neutral with regard to jurisdictional claims in published maps and institutional affiliations.

Ready to submit your research? Choose BMC and benefit from:

- fast, convenient online submission

- thorough peer review by experienced researchers in your field

- rapid publication on acceptance

- support for research data, including large and complex data types

- gold Open Access which fosters wider collaboration and increased citations

- maximum visibility for your research: over $100 \mathrm{M}$ website views per year

At BMC, research is always in progress.

Learn more biomedcentral.com/submissions 